\title{
Design of a solar district heating system with seasonal storage in Italy
}

\author{
Michele Salvestroni ", Giacomo Pierucci, Atabak Pourreza, Federico Fagioli, Francesco Taddei, \\ Matteo Messeri, Maurizio De Lucia
}

Department of Industrial Engineering, University of Florence, Via di Santa Marta 3, 50139 Florence, Italy

\section{A R T I C L E I N F O}

\section{Keyword:}

Water tank seasonal energy storage

Solar district heating

TRNSYS

Numerical modeling

\begin{abstract}
A B S T R A C T
The residential sector is responsible for $26 \%$ of final energy consumption in the European Union. A key strategy to reduce household fossil fuel use is solar district heating with seasonal thermal energy storage. Although this technology has been widely applied in Northern Europe (Sweden, Denmark, and Germany), it has not been implemented in Italy. This research presents a new numerical tool, and applies it to the REPLICATE project in the Italian city of Florence, which is financed under the Horizon 2020 Smart Cities and Communities initiative. Our novel tool, which is based on a dynamic model coupled with the finite element method, has been developed to guide the design of the district heating plant and obtain a reliable estimation of performance, notably storage heat losses. The overall aim is to reduce the prediction inaccuracies that have characterized past projects. The final dynamic model is implemented in TRNSYS, and makes it possible to select the main plant parameters and define control strategies. It is linked to a detailed heat transfer model developed in COMSOL Multiphysics ${ }^{\circledR}$, which can calculate storage heat losses and determine the optimal thickness of insulation material. Our in-depth parametric study determined the optimal volume of the hot water tank to be $3800 \mathrm{~m}^{3}$, and the size of the solar field to be $1000 \mathrm{~m}^{2}$. We also evaluated the effectiveness of the addition of a water-water heat pump. This analysis found that it is a crucial component as it can increase storage capacity and improve the performance of solar collectors by up to $124 \mathrm{MWh}$. Our results indicate that with an optimized configuration, the solar fraction of the system can reach up to $44 \%$.
\end{abstract}

\section{Introduction}

Globally, the energy consumption of residential and service sector buildings has significantly increased in past decades [1]. In the European Union (EU) in particular, all buildings are responsible for around $40 \%$ of total consumption [2], and the residential sector for $26 \%$ [3]. Consumption in the latter sector has grown significantly since 2000 [4] and the vast majority (78\%) is used for space heating and domestic hot water [3]. In 2019, most energy for heating and cooling was produced from fossil fuels ( $75 \%$ of the total), while renewable sources only provided $22 \%$ [5]. In order to reduce fossil fuel consumption and greenhouse gas emissions in the residential sector, the EU is pursuing several strategies, notably: more extensive use of photovoltaic panels and solar thermal collectors by households [6]; the electrification of heating through the use of highly-efficient heat pumps [2]; the renovation of existing energy-inefficient buildings [2]; and the implementation of district heating networks fed by waste heat and renewable sources [7]. In this context, new concepts are emerging, such as the Positive Energy District (PED), which is defined as an urban neighborhood characterized by annual net zero energy import and net zero $\mathrm{CO}_{2}$ emissions, with surplus production of renewable energy integrated into an urban and regional system. A PED is thus characterized by a high level of building efficiency, which is achieved by retrofitting and the introduction of renewable energy sources [8].

In the domain of solar technologies, recent years have seen the widespread diffusion of photovoltaic panels and solar thermal collectors in residential sectors to meet demand for electricity, space heating and domestic hot water (DHW). Solar thermal collectors, in particular, are very interesting, as most household energy is needed for heating. These

\footnotetext{
Abbreviations: CFD, computational fluid dynamics; COP, coefficient of performance of the heat pump; DHW, domestic hot water; DNI, direct normal irradiance;

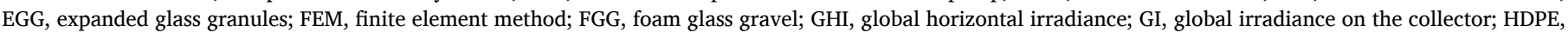

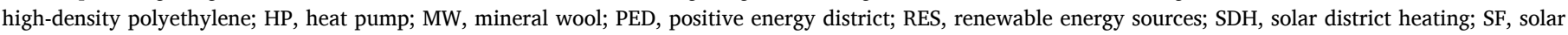
field; STES, seasonal thermal energy storage.

* Corresponding author.

E-mail address: michele.salvestroni@unifi.it (M. Salvestroni).
} 


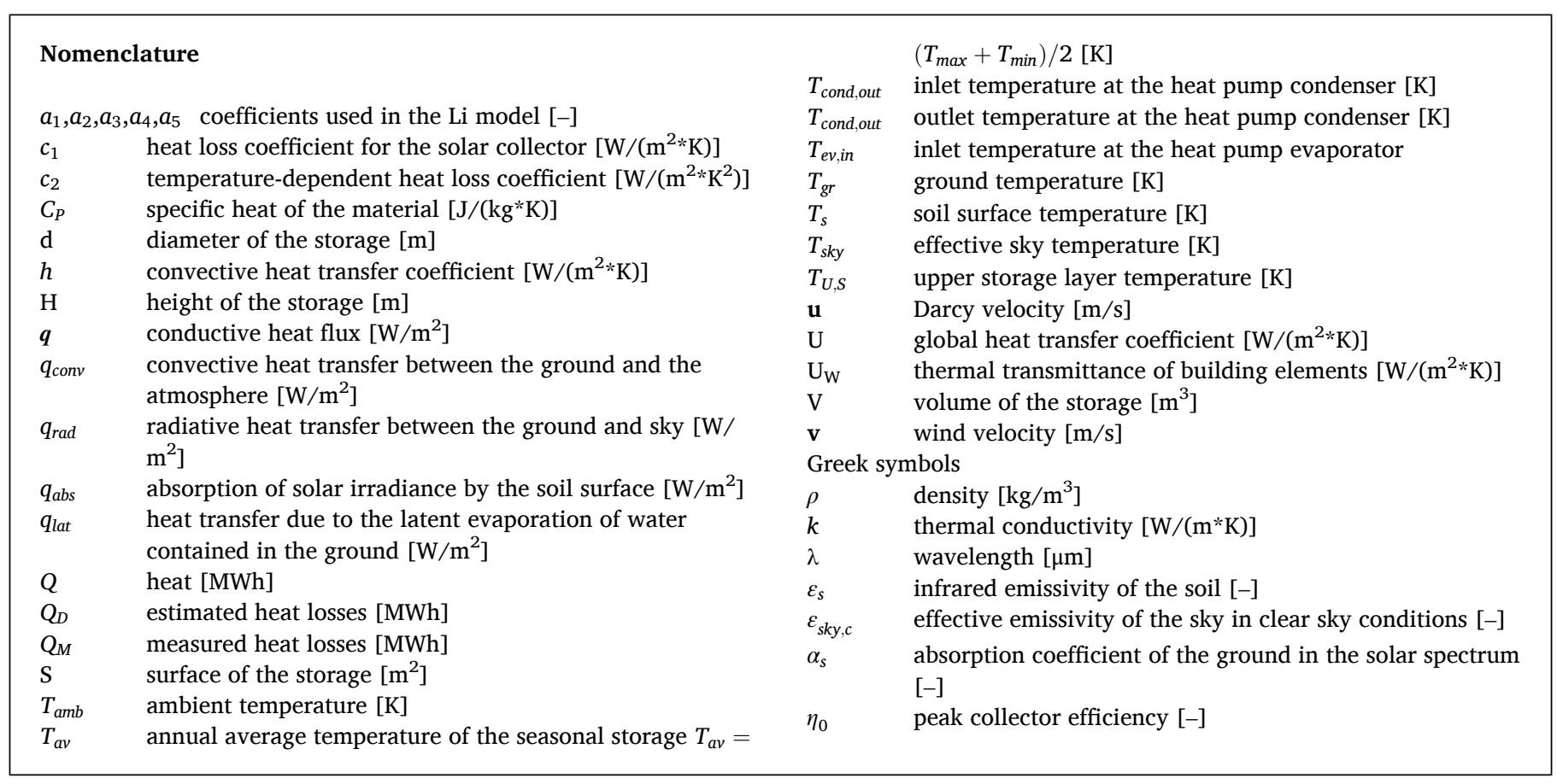

systems are characterized by their scalability, ranging from small installations for single-family houses to large-scale plants. Large-scale applications, covering thousands of square meters, can satisfy the thermal needs of an entire small town or urban quarter, via a district heating network. In recent years, several of these solar district heating (SDH) systems have been implemented in the EU [9]. Nevertheless, the impact of solar thermal technologies remains limited: for instance, in 2019, in Italy they met only met $0.4 \%$ of heating and cooling demand [10].

The main disadvantage of solar technologies is related to their intermittence nature that causes failure in meeting the energy demand and supply [11]. However, for solar thermal collectors a valid and economic solution to tackle this problem is already available and it is represented by the use of a sensible energy storage which allows to store heat in a storage medium, in general water, increasing its temperature. Therefore, the potential surplus of heat produced by solar thermal collectors can be easily stored and release it subsequently when needed by users. If theperiod of storage is long up to several months, the thermal storage is called seasonal (STES). Applying this concept to solar thermal collectors in residential sector, STES allows in theory to store the excess of heat produced by solar thermal collectors during spring and summer when the thermal needs are low and to deliver it during winter when the heat demand is high [12]. Therefore, STES makes available on-demand the energy produced, overcoming the problem of intermittence of the source. Thanks to STES, it is possible to raise considerably the amount of heat provided by solar energy respect to the total heat demand, which is called solar fraction [13]. For all of these reasons, solar district heating systems are in general realized in association with STES. SDH with STES is one of the most interesting strategies to decarbonize the residential sector [11].

Concerning STES, four different typologies of storage have been developed: aquifer, borehole, pit and tank [14]. Aquifer storage exploits ground water to store heat. Borehole storage stores heat underground; it is then delivered to users through pipes. Pit storage consists of an artificial pool filled with a storage material (water, or water mixed with gravel) that is covered by a roof and has walls that are lined by uninsulated watertight plastic foil. Tank storage consists of structures that are made of concrete or stainless steel surrounded by thick insulation to reduce thermal losses [15]. A liner (stainless steel or polymer) and a vapor barrier protect the insulating material and avoid water permeation, respectively [16]. While aquifer and borehole storage are, by definition, underground solutions, pit and tank storage can be built overground. However, they are preferentially realized underground to better integrate them in residential areas since they are in general characterized by large volumes (thousands of cubic meters); moreover, the ground adds to the insulation. The choice of technology depends on the specific application, notably geological, thermal and economic considerations [11].

Many examples of SDH with STES have been implemented in recent years. Their solar fraction ranges from 20 to $50 \%$ [11]. In general, the highest values are reached by coupling STES with a heat pump, which can fully discharge the stored energy [17]. In 1980, Sweden was the first country to invest in this technology [18]; Denmark and Germany are currently the leading countries in Europe [19]. By the end of 2017, over 100 SDH projects had been implemented in Denmark, and 1.3 million $\mathrm{m}^{2}$ of solar collectors had been connected to district heating systems [20]. Seasonal storages, notably especially pit storages, have been realized in several of these projects. One of the first successful SDH was built in Marstal [21], and it is characterized by $33,000 \mathrm{~m}^{2}$ of solar collectors and $75,000 \mathrm{~m}^{3}$ of pit storage. Water is the storage medium, the pit has a high-density polyethylene liner and the water is covered by a floating insulating cover. A heat pump discharges stored heat up to $10{ }^{\circ} \mathrm{C}$. Gram (pit storage of $122,000 \mathrm{~m}^{3}$ and $45,000 \mathrm{~m}^{2}$ of solar collectors) and Dronninglund $\left(62,000 \mathrm{~m}^{3}\right.$ pit storage with $38,000 \mathrm{~m}^{2}$ of solar collectors) are two other examples of major SDH systems in Denmark [22]. In both cases, the storage is used to deliver directly the heat to users and indirectly exploiting it as a heat source for absorption or compression heat pumps [23]. Several SDH systems with seasonal storage (tank, pit, borehole, aquifer) have been built in Germany [24], and the country is a major contributor to research on underground hot water tanks. Tank volume ranges from a few hundred cubic meters to $12,000 \mathrm{~m}^{3}$. The first demonstration projects of solar district heating with STES were implemented in 1996 in Hamburg and Friedrichshafen [25]. Different construction materials have been used, such as concrete with a stainless steel liner (Friedrichshafen [26], Hamburg [25], Munich [27]), waterproof concrete without liner (Hanover [28]), or fiber reinforced resin (Ilmenau [29]). Several pit storage solutions have also been built (Stuttgart, Chemnitz, Augsburg, Eggstein); here, the storage medium is a mixture of gravel and water, sand and water, or soil and water [30]. 
To date, there are no operational SDH with STES in Italy. However this technology could be extremely interesting for Italy since the solar resource is higher than in northern Europe. Many Italian cities already have district heating nets that are $75 \%$ fed by fossil fuels, with the remainder coming from waste and geothermal energy [31]. A prototype system was built in Cosenza in 1995 to provide space heating for a 1750 $\mathrm{m}^{3}$ building [32]. A $91.2 \mathrm{~m}^{2}$ solar field provided heat directly to the building and to a $500 \mathrm{~m}^{3}$ water tank made of reinforced concrete equipped with $0.20 \mathrm{~m}$ foam glass insulation [33]. More recently, three projects of solar district heating without STES have been developed: for example, in Varese around $1000 \mathrm{~m}^{2}$ of flat plate collectors have been connected to the net [34].

In general, SDH system with STES must be large scale to be costeffective. As this requires significant financial investment, the design phase is crucial [11]. Design starts with, among other considerations, the determination of the district's heat demand, the identification of the area available for the solar field and the STES, and the target solar fraction. The design of the STES is particularly complex as it involves not only structural considerations, but also geological aspects, and energetic and economic issues. Taking the example of water tank storage, thermal performance is significantly affected by many factors: geometric parameters such as the aspect ratio, and surface to volume ratio; the structure and properties of materials (thermal properties of materials, water tightness, layer width, etc.); and external constraints such as ground characteristics, radiation resources, user demand, size of the solar field, supply and return temperatures, etc. [11]. So that, due to complexity of the STES design, a numerical analysis is required to study all the parameters that can affect the overall system.

Generally, the numerical analysis is divided into several steps that are characterized by different levels of detail and complexity. Initially, simplified numerical models provide a rough estimation of the size of the solar field and storage requirements. For instance, [35] developed a tool using engineering equation solver (EES) software for the pre-design stage. The second step is an in-depth analysis of the seasonal storage and its interaction with the district heating net. Here, more complex models developed using energy system simulation software (TRNSYS, MODELLICA, DYMOLA) are needed. The appropriate software is selected based on the aim of the simulation, the component of the SDH to be modelled, and the degree of detail needed [36].

TRNSYS [37] is the most widely-used thermal process simulation software package, and it can model renewable energy systems such as SDH with STES. Solving for energy flows that enter and exit each component, called 'types', results in an estimate of the heat collected by the solar field, the influence and interactions between different components of the SDH system (boilers, heat pumps, etc.), the thermal behavior of the STES, etc. It can be used to evaluate how the system operates over long periods of time, such as years, at hourly or sub-hourly intervals, and requires limited computational resources. However, it fails to accurately predict STES heat losses, due to a simplified approach to heat transfer to the surrounding ground [11]. Moreover, as it does not solve for fluid flow inside the storage system, it does not take into account phenomena such as buoyancy and mixing at inlet ports. Therefore, it is unable to accurately estimate thermal stratification in the storage solution.

A detailed insight into the thermo-hydraulic behavior of STES is given by computational fluid dynamics (CFD). However, a multi-annual, transient 3D thermo-fluid dynamic analysis of a large-scale STES (containing thousands of cubic meters) remains a challenging task, as significant computation resources are required [11]. Few CFD models of large underground storage systems have been developed. Panthalookaran et al. [38], realized a turbulence CFD model to describe charging/discharging operations of STES. The study compared the results of the simulations with experimental data measured in two tank STES located in Germany (Friedrichshafen and Hanover) and found that the results of the simulation were in good agreement with experimental data. However, the period of time of the simulation was limited to $5 \mathrm{~h}$. A numerical model of a pit STES is developed in Chang et al. [39]. Their model focuses on natural convection and temperature stratification, and was validated with experimental data from a lab test. Fan et al. [40] developed a CFD model of the Marstal pit STES, in order to describe the distribution of temperature inside. The model has been validated with the experimental results, reproducing accurately short term behavior (few hours) of the STES during charge and discharge operations.

The above observations highlight that current energy simulation models do not include all of the relevant details; at the same time, CFD models are infeasible given the time and computational resources that are required. Consequently, past numerical models based on energy simulations software have failed to correctly predict STES heat losses and the general performance of the SDH. Specifically, most measured values of STES heat losses deviate significantly from estimates (by $30-450 \%$ ) [29] and the actual solar fraction of the realized SDH is in some cases $50 \%$ lower than calculated values [24]. Thus, a novel, robust numerical procedure is needed to guide the design of such systems.

This paper addresses the problem. We develop an innovative numerical analysis that can accurately predict the performance of the SDH plant and the STES. The novelty of our work is that it couples a dynamic SDH model with a FEM heat transfer model of the STES. To the best of our knowledge, this is the first time that such an analysis has been carried out to guide the design of the plant. The overall aim is to produce a reliable estimation of STES heat losses and the performance of the plant, and limit the prediction inaccuracies that have characterized past projects. Our analysis is based on the development of various numerical models in several software packages (Tas EDSL [41], TRNSYS [37], and COMSOL Multiphysics ${ }^{\circledR}[42]$ ). This paper focuses on the design of the SDH system with STES that is currently being developed for Florence, Italy. The city of Florence is part of the EU's REPLICATE project, financed under the Horizon 2020 Smart Cities and Communities program. The plan is to improve the energy performance of two social housing projects (299 dwellings) by implementing a small SDH system with STES-for the first time in Italy.

Section 2 of this study describes the specific features of the Florence project and the preliminary part of the numerical analysis. The SDH model (using TRNSYS) and the STES FEM model are presented in Section 3 , while the obtained results are reported in Section 4. Finally, Section 5 presents our conclusions.

\section{Pre-design}

\subsection{The numerical procedure}

Our analysis is based on numerical models that are developed in linked software packages. The model of the SDH has been realized with TRNSYS. However, as observed in the introduction, TRNSYS oversimplifies the analysis of the heat transfer between the STES system and the ground. One of the main pitfalls of past projects has been the erroneous prediction of thermal losses in the storage tank, due to the inability of dynamic models to capture all of the relevant aspects. A detailed FEM model would overcome this problem, as it can take into account the influence of the external environment (ground and atmospheric radiation) on the STES envelope temperature and provide a reliable estimation of heat losses. Such a model should be able to pass the information that is obtained to TRNSYS. However, a transient thermo-fluid dynamic model that is able to describe both heat transfer between the STES and the ground, and fluid flow inside the storage system (resulting from buoyancy and fluid inlet/outlet through ports) is too costly from a computational point of view. Consequently, this kind of model is unsuitable for a high number of simulations, which is usually the case during the design of an SDH system. A faster, more flexible tool is needed. Our FEM model can capture several crucial aspects, such as the STES geometry, its thermal bridges, and the distribution of soil temperature due to underground heat transfer mechanisms, which are not considered in the TRNSYS model. 
An overview of our numerical procedure is shown in the block diagram below (Fig. 1). It is based on several numerical models that are developed in linked software packages. The first step is to evaluate user heat demand by developing a dynamic model of the buildings in Tas. Then, a complete model of the SDH plant (solar field, seasonal storage, heat pump, gas boiler, etc.) is implemented in TRNSYS. Heat demand (calculated in the previous step with Tas) is used as the boundary condition in the TRNSYS model. The model is able to describe the dynamic behavior of each component, and can highlight the parameters that have most influence on performance.

In order to improve the accuracy of heat loss calculations, and estimate the optimal thickness of the insulating material, a 2D axisymmetric FEM model of the STES was developed in COMSOL Multiphysics ${ }^{\circledR}$ 5.2. The FEM model was then integrated into TRNSYS simulations in an iterative procedure, as follows. First, a preliminary TRNSYS simulation was run, which set the value of the heat transfer coefficient as $0.05 \mathrm{~W} /$ $\left(\mathrm{m}^{2} \mathrm{~K}\right)$, and determined the annual temperature profile within the STES. Then, this temperature profile was applied to the interior boundaries of the storage of FEM model. FEM simulations were run to calculate heat loss through the systems' walls. TRNSYS simulations were updated with the heat transfer coefficient determined by the FEM model, and a new STES temperature profile was obtained. This new profile was used to recalculate heat losses in the FEM model. When the relative difference between the two solutions fell below $1 \%$, the iteration ended. Next, a parametric analysis was carried out to select the thickness of the insulation layer. The above iterative procedure was repeated for each value of insulation thickness. Once heat losses for each thickness had been determined, and the optimum thickness for the application had been selected, the results were used as input to the TRNSYS model. Finally, a parametric analysis was run in TRNSYS; the main parameters (STES

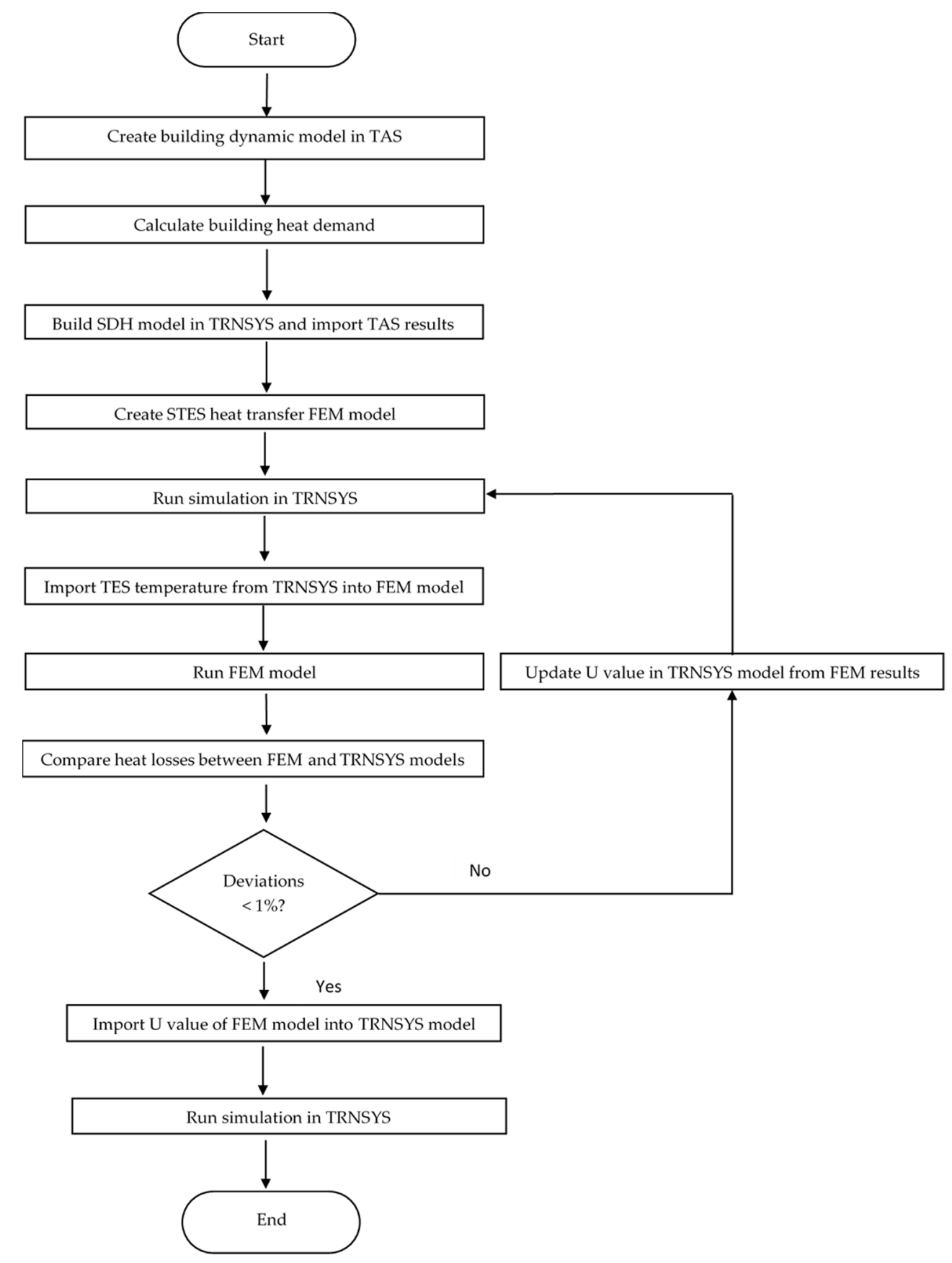

Fig. 1. Flow chart of the numerical procedure. 
volume, heat pump capacity, etc.) were varied to obtain the optimal solution for the SDH plant.

\subsection{The project of the SDH with STES in Florence}

The SDH and the seasonal storage will be built in Florence, Italy $\left(43^{\circ} 46^{\prime} \mathrm{N} 11^{\circ} 15^{\prime} \mathrm{E}\right)$. The aim is to supply heat to two existing buildings, each with six floors, making a total of 299 dwellings. The system is expected to provide up to $40 \%$ of heat demand thanks to heat that is collected during the summer months (when solar resource is high and demand is low) and stored in the seasonal storage. First, the two buildings will be retrofitted with external insulation, in order to improve thermal performance and reduce space heating demand. Currently, space heating is supplied by individual gas boilers. These will be replaced by a centralized gas boiler, which will provide heat to radiators in individual homes (which cannot be substituted). Supply and return temperatures are, respectively, $66^{\circ} \mathrm{C}$ and $50{ }^{\circ} \mathrm{C}$. The area for the solar field is limited to the buildings' roofs, which amounts to $1670 \mathrm{~m}^{2}$ (Fig. 2). The area available for heat storage is limited to the space between the two buildings. As the municipality forbids any above-ground structures close to the river Arno due to flooding, the STES must be fully underground. The area's geologic characteristics make it unsuitable for borehole or aquifer storage; thus, the options are restricted to pit or tank. The presence of an aquifer, $12 \mathrm{~m}$ below ground level, limits the height of the proposed solution, since contact must be avoided to reduce heat losses. There are no significant limitations with respect to its other dimensions. A comparison of pit and water tank storage led to the selection of the latter one as the appropriate choice for the project, thanks to its better thermal insulation [15]. The maximum temperature of water inside the STES will be limited to $95{ }^{\circ} \mathrm{C}$ as the tank will not be pressurized.

\subsection{Dynamic model of the two buildings}

The numerical analysis began with the development of a dynamic model in Tas (EDSL, version 9.3.3). Here, the aim was to calculate buildings heat demand after retrofitting. TAS EDSL is a simulation tool that allows to perform hourly dynamic thermal simulation for buildings
[41]. Structural elements, such as walls, roofs, floors and windows are designed in a 3D environment (Fig. 3), and the software calculates the annual space heating demand of the building envelope once the main boundary conditions for thermal zones have been fixed.

Building features and annual radiation data for Florence, taken from the ASHRAE typical meteorological year that has been used for simulations [44] are reported in Table 1.

The main boundary conditions for the simulation are reported in Table 2. Under Italian law, the heating period for the city of Florence runs from November 1 to April 15 [45], and the number of hours per day of space heating must not exceed $12 \mathrm{~h}$. No cooling system will be installed.

The two buildings' structural elements after retrofitting, and thermal transmittance values are reported in Table 3.

DHW needs were calculated based on Italian Technical Specifications [45]. The average EU hourly profile of DHW heat demand for households has been taken from [46]. DHW demand has been assumed constant each day of the year. The results of the dynamic simulation are reported in Table 4. Total heat demand for the two buildings, neglecting losses, is calculated to be $1142 \mathrm{MWh} / \mathrm{yr}$.

Hourly space heating demand for the two buildings, normalized to annual space heating demand obtained from simulations is reported in Fig. 4.

\subsection{The solar field model}

TRNSYS 17 was used to optimize the configuration of solar collectors and maximize the amount of heat collected, as the space for the solar field is limited. Only the solar field was modelled in this phase. However, in practice, operational conditions for the solar collectors could be very different to the simple situation that was modelled, notably because they are highly dependent on STES capacity and heat demand. Therefore, a complete model of the SDH system, including all of its components and connections is needed.

High-performance evacuated solar collectors (rather than flat plate collectors) have been selected for the project as they are characterized by lower heat losses at higher temperatures. This is relevant because the supply temperature of space heating is relatively high $\left(66^{\circ} \mathrm{C}\right)$ and the

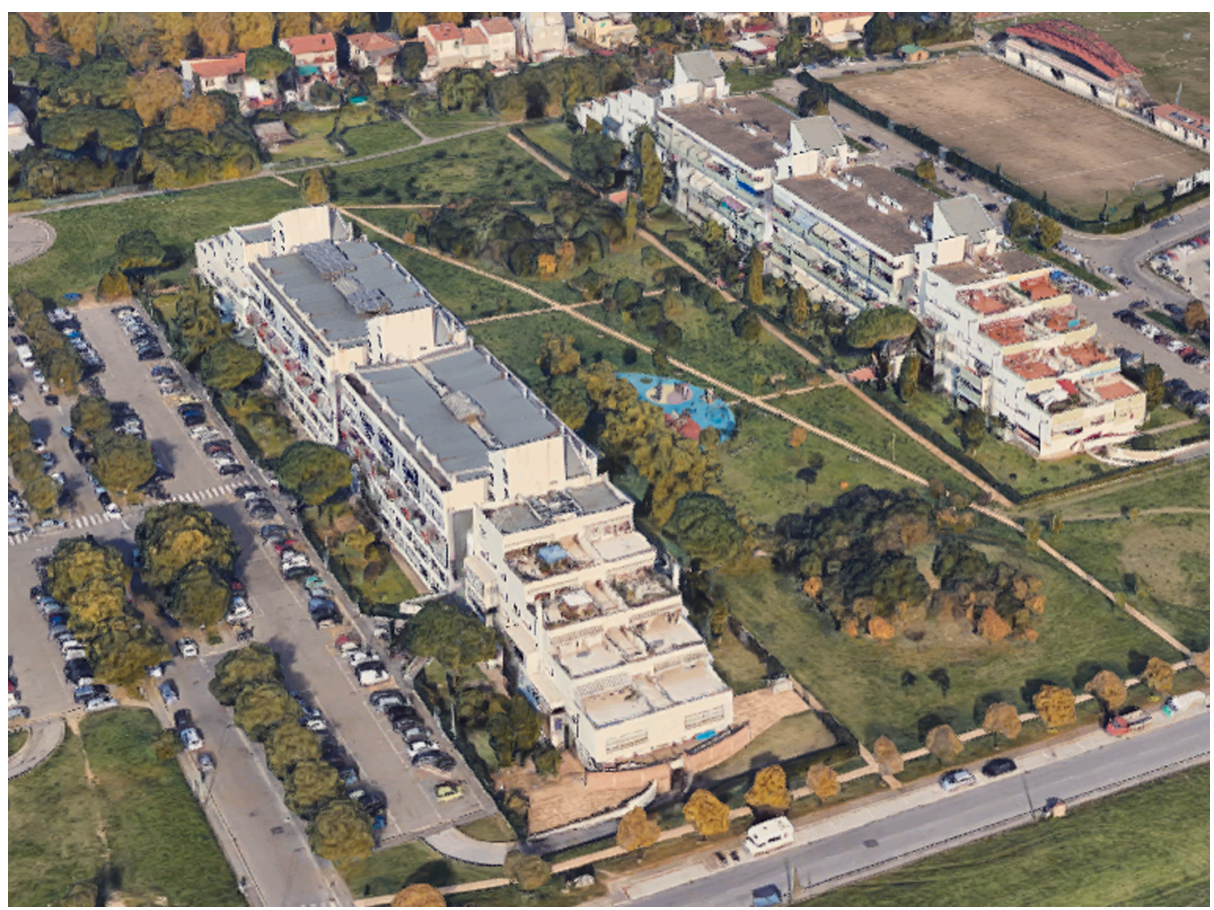

Fig. 2. Buildings and the area covered by the project [43]. 


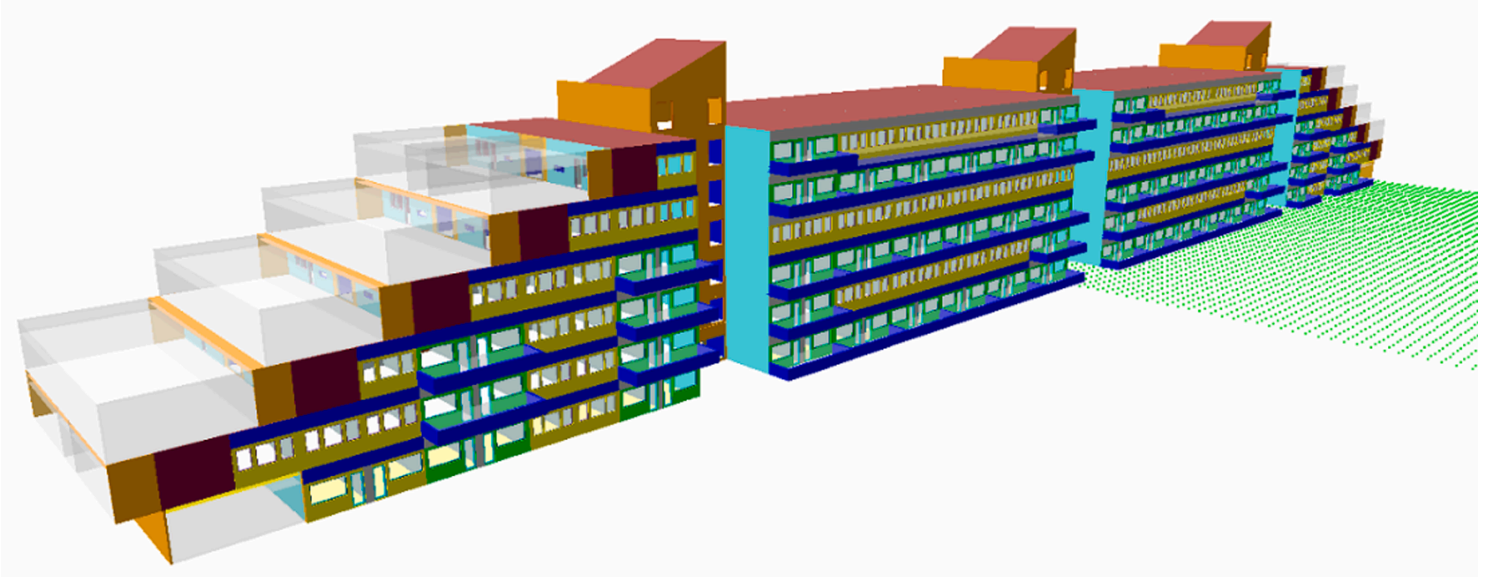

Fig. 3. Geometry of one of the buildings simulated in Tas.

Table 1

Building features, annual global horizontal irradiance (GHI) and direct normal irradiance (DNI) for Florence [44].

\begin{tabular}{ll}
\hline Main parameters & \\
\hline Total net surface & $20,207 \mathrm{~m}^{2}$ \\
Building orientation & $5^{\circ}$ East, with respect to the N-S axis \\
Number of dwellings & 299 \\
GHI & $1428 \mathrm{kWh} /\left(\mathrm{m}^{2} \mathrm{yr}\right)$ \\
DNI & $1419 \mathrm{kWh} /\left(\mathrm{m}^{2} \mathrm{yr}\right)$ \\
\hline
\end{tabular}

Table 2

Boundary conditions for the simulation in accordance with Italian regulations [45].

\begin{tabular}{ll}
\hline Boundary conditions & \\
\hline Air change per hour & $0.3 \mathrm{~h}^{-1}$ \\
Internal temperature & $20{ }^{\circ} \mathrm{C}$ \\
Internal gains & $6 \mathrm{~W} / \mathrm{m}^{2}$ \\
Latent gains & $250 \mathrm{~g} / \mathrm{hour}$ \\
\hline
\end{tabular}

Table 3

Structural elements of the two buildings and their thermal transmittance.

\begin{tabular}{ll}
\hline Building element & $\mathrm{U}_{\mathrm{w}}\left[\mathrm{W} /\left(\mathrm{m}^{2} \mathrm{~K}\right)\right]$ \\
\hline External concrete wall & 0.22 \\
Insulated external wall & 0.16 \\
External wall & 0.20 \\
Internal wall & 1.4 \\
Ground floor & 1.2 \\
Ceilings & 0.22 \\
Insulated roof & 0.19 \\
Window type 1 & 3.4 \\
Window type 2 & 3.8 \\
Window type 3 & 3.4 \\
\hline
\end{tabular}

Table 4

Annual heat demand for the two buildings.

\begin{tabular}{ll}
\hline Annual heat demand & [MWh] \\
\hline Space heating & 809 \\
Domestic hot water & 333 \\
\hline
\end{tabular}

maximum charging temperature of the STES system is around $95{ }^{\circ} \mathrm{C}$. Parameters for the evacuated collectors used in simulations are reported in Table 5. TRNSYS type 71 was used to model behavior of the solar collectors.

Incidence angle modifier data for the collector were included to account for decreasing performance due to off-normal solar incidence. Mutual shadowing between collectors, and external shadows caused by the buildings' towers was also considered. The simulation was run for a constant inlet flow temperature of $80{ }^{\circ} \mathrm{C}$. Table 6 shows the results of several configurations. The gross occupied area remains constant, while collector tilt and the distance between them is varied.

As Table 6 shows, annual heat production is maximized by filling the available area with the maximum number of collectors and reducing the distance between rows. This the optimal configuration, even if mutual shadows could occur during the morning and evening, and the tilt of the collectors diverges from the theoretical angle that maximizes annual output for a single collector (around $36^{\circ}$ in Florence).

\subsection{Water storage tank design considerations}

Two important geometric parameters for STES performance are the surface to volume ratio (S/V), given by the surface of STES divided by the volume of the STES, and the aspect ratio, i.e., the ratio of height to diameter $(\mathrm{H} / \mathrm{d})$. In particular, the $\mathrm{S} / \mathrm{V}$ represents the ratio between heat losses and thermal capacity of storage [14]. Since the surface is proportional to the square of the length, and the volume is proportional to the cube of the length, an increase in volume decreases the ratio and, therefore, heat losses with respect to stored heat. The aspect ratio, in turn, has a significant influence on temperature stratification, and is linked to internal exergetic losses [48]; high aspect ratios increase stratification. Furthermore, taking the simple shape of a cylinder, it is well-known that an aspect ratio of $1(\mathrm{~h}=\mathrm{d})$ minimizes the surface and, therefore, heat losses. The main geometric features of existing underground, or partially underground systems in Germany are reported in Table 7.

There is little experimental data about the operational performance of STES. Table 8 reports performance data for four tank STES built in Germany, which are characterized by different kinds and thicknesses of insulation material. The STES in Hamburg have no insulation at the bottom. In Hanover and Munich, its thickness varies: it is thinnest at the bottom ( $0.3 \mathrm{~m}$ and $0.2 \mathrm{~m}$, respectively), and thicker at the sides and top ( $0.7 \mathrm{~m}$, for both). It can be noted from Table 8 that measured heat losses are significantly higher than values estimated during the design phase, by $30-350 \%$, or even more. Several factors may explain this mismatch [29], they include: moving groundwater at the bottom of the storage 


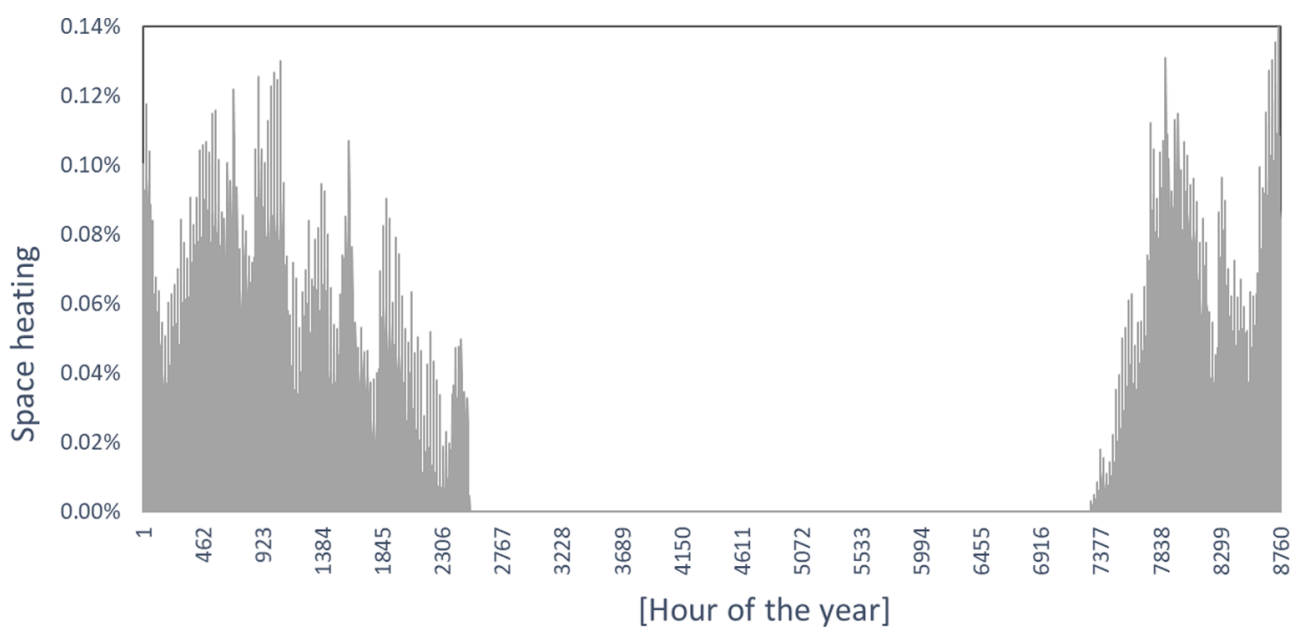

Fig. 4. Hourly profile of space heating demand in the two buildings.

Table 5

Performance parameters of the solar collector [47]. The parameters refer to gross area.

\begin{tabular}{ll}
\hline Parameters of the solar collector & \\
\hline$\eta_{0}$ & 0.641 \\
$c_{1}$ & $0.935 \mathrm{~W} /\left(\mathrm{m}^{2} \mathrm{~K}\right)$ \\
$\mathrm{c}_{2}$ & $0.004 \mathrm{~W} /\left(\mathrm{m}^{2} \mathrm{~K}^{2}\right)$ \\
Gross area & $3.86 \mathrm{~m}^{2}$ \\
\hline
\end{tabular}

Table 6

Comparison of solar field layouts. The analysis considers the number of rows, the distance between rows, collector tilt, the net area occupied, and the total energy collected.

\begin{tabular}{lllll}
\hline $\begin{array}{l}\text { Number of } \\
\text { rows }\end{array}$ & $\begin{array}{l}\text { Distance } \\
\text { between rows } \\
{[\mathrm{m}]}\end{array}$ & $\begin{array}{l}\text { Tilt } \\
{\left[{ }^{\circ}\right]}\end{array}$ & $\begin{array}{l}\text { Net area occupied } \\
\text { by collectors }\left[\mathbf{m}^{2}\right]\end{array}$ & $\begin{array}{l}\text { Heat collected } \\
{[\mathrm{MWh} / \mathbf{y r}]}\end{array}$ \\
\hline 28 & 2.1 & 25 & 504 & 354 \\
44 & 1.1 & 15 & 792 & 544 \\
48 & 0.8 & 15 & 864 & 585 \\
56 & 0.5 & 10 & 1008 & 687 \\
\hline
\end{tabular}

Table 7

Tank STES in Germany, and their main geometric parameters. .

\begin{tabular}{llllll}
\hline Location & Year & $\mathbf{V}\left[\mathbf{m}^{\mathbf{3}}\right]$ & $\mathbf{S}\left[\mathbf{m}^{2}\right]$ & $\mathbf{h} / \mathbf{d}[-]$ & $\mathbf{S} / \mathbf{V}[\mathbf{1} / \mathbf{m}]$ \\
\hline Hamburg & 1996 & 4500 & 1650 & $10.7 / 25.7$ & 0.37 \\
Friedrichshafen & 1996 & 12,000 & 2796 & $19.4 / 32.4$ & 0.23 \\
Ilmenau & 1998 & 300 & 262 & $8.0 / 7.2$ & 1.14 \\
Hanover & 2000 & 2750 & 1135 & $11.1 / 19.0$ & 0.41 \\
Attenkirchen & 2001 & 500 & 350 & $8.0 / 8.9$ & 0.70 \\
Crailsheim & 2006 & 480 & 362 & $14.5 / 6.3$ & 0.75 \\
Munich & 2006 & 6000 & 1800 & $16.1 / 24.6$ & 0.30 \\
\hline
\end{tabular}

Adapted from [11] system, higher thermal conductivity of the insulation material due to higher STES temperatures and moisture penetration, higher return temperature from the district net, and poor thermal stratification inside the tank.

For structural reasons, a truncated cone shape has been chosen for the storage tank in Florence. The size of the construction site (see Section 2.2) and the presence of the aquifer meant that the bottom of the tank could not be more than about $8 \mathrm{~m}$ below ground level. However, exploiting an existent small hill over the ground, the maximum internal height could be around $12 \mathrm{~m}$; thus, the height available for water, considering thermal expansion, is around $9.8 \mathrm{~m}$. The ideal aspect ratio for a cylindrical tank is consistent with a storage volume of $650 \mathrm{~m}^{3}$. Assuming annual internal tank storage temperatures $\mathrm{T}_{\min }=25^{\circ} \mathrm{C}$ and $\mathrm{T}_{\max }=95{ }^{\circ} \mathrm{C}$, the storage capacity is $52 \mathrm{MWh}$, which that is too low compared to the heat demand and for reaching the targeted solar fraction of up to $40 \%$. Volume can only be increased by increasing the diameter (i.e., lowering the aspect ratio). This is likely to have two consequences: less thermal stratification, and a higher S/V ratio compared to the ideal one with the same volume. Geometric parameters and capacity for different storage volumes are reported in Table 9 (capacity is calculated assuming $\mathrm{T}_{\min }=25^{\circ} \mathrm{C}$ and $\mathrm{T}_{\max }=95^{\circ} \mathrm{C}$ ). As can be noted from Table 9 , the surface to volume ratio decreases rising the volume. However, a comparison of the proposed system with the much bigger Munich tank shows that the ratio remains significantly higher (by 23\%).

For financial reasons, as at Hanover [29], the main construction

Table 9

Geometrical parameters of the tested storage configurations.

\begin{tabular}{lllll}
\hline $\mathrm{V}\left[\mathrm{m}^{3}\right]$ & $\mathrm{S}\left[\mathrm{m}^{2}\right]$ & $\mathrm{H} / \mathbf{d}[-]$ & $\mathrm{S} / \mathrm{V}[\mathbf{1} / \mathrm{m}]$ & Storage Capacity $[\mathrm{MWh} / \mathrm{yr}]$ \\
\hline 1500 & 740 & $9.8 / 14.2$ & 0.49 & 122 \\
2500 & 1075 & $9.8 / 18.2$ & 0.41 & 204 \\
3800 & 1452 & $9.8 / 24$ & 0.39 & 310 \\
4800 & 1812 & $9.8 / 28$ & 0.38 & 391 \\
5800 & 2145 & $9.8 / 31.4$ & 0.37 & 473 \\
\hline
\end{tabular}

Table 8

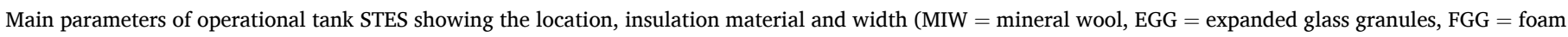

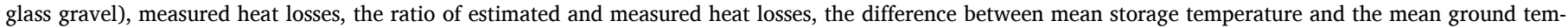
perature, the heat transfer coefficient, and the measured solar fraction [11,24,26,29,49-51,52].

\begin{tabular}{|c|c|c|c|c|c|c|}
\hline Location & Insulation & $\mathrm{Q}_{\mathrm{M}}[\mathrm{MWh} / \mathrm{yr}]$ & $\mathrm{Q}_{\mathrm{D}} / \mathrm{Q}_{\mathrm{M}}[\mathrm{MWh} / \mathrm{yr}]$ & $\mathrm{T}_{\mathrm{av}}-\mathrm{T}_{\mathrm{gr}}[\mathrm{K}]$ & $\mathrm{U}\left[\mathrm{W} /\left(\mathrm{m}^{2} \mathrm{~K}\right)\right]$ & Solar Fraction [\%] \\
\hline Hamburg & $0.3 \mathrm{~m}$ MIW & $360-430$ & $3.8 / 4.5$ & 42 & $0.6 / 0.71$ & 25 \\
\hline Friedrichshafen & $0.3 \mathrm{~m}$ MIW & $320-480$ & $1.5 / 2.2$ & 49 & $0.25 / 0.28$ & $21-33$ \\
\hline Hanover & 0.3/0.7 m MIW/ EGG & $90-100$ & $1.3 / 1.4$ & 33 & $0.28 / 0.31$ & - \\
\hline Munich & $0.2 / 0.7 \mathrm{~m}$ FGG and EGG & 195 & 2.4 & - & - & 45 \\
\hline
\end{tabular}


material will be watertight high-density concrete with low vapor permeability, rather than concrete with a steel liner. Among the various type of insulation materials that are employed in tank STES (e.g., XPS, EPS, mineral wool, expanded glass) bulk materials such as expanded glass granules have been used in recent projects [15]. The fact that they can be poured makes them a simpler and more economical solution than mounting insulation sheets [51]. They were selected as the insulation material for the side walls and top of the Florence STES. Foam glass will be used at the bottom because of its resistance to static pressure. A highdensity polyethylene (HDPE) vapor barrier has been chosen to protect the insulator from ground moisture penetration. The configuration of the STES wall is reported in Fig. 5.

\section{Numerical analysis}

\subsection{The TRNSYS model of the SDH system}

The overall SDH system was modelled in TRNSYS (version 17). This model describes all of the components of the plant (STES, the solar field, the heat pump, the backup boiler) and their connections. Heat demand, calculated in Tas, is used as an input to the TRNSYS model. Fig. 6 shows the layout of the SDH. It is divided into loops that represent different hydraulic circuits (solar, STES, and user).

Several differential (type 2b) controllers govern operations. For instance, the solar field pump is only switched on if solar radiation is above $150 \mathrm{~W} / \mathrm{m}^{2}$. The solar field is modelled by type 71 , which describes an evacuated tube collector. The performance of the solar collector is described by:

$\eta=\eta_{0}-c_{1}\left(T_{M}-T_{a m b}\right) / G I-c_{2}\left(T_{M}-T_{a m b}\right)^{2} / G I$

where $T_{M}$ is the mean temperature of the collector, and GI is global irradiance on the collector. Performance parameters of the evacuated solar collectors are taken from [47]. When $G I>0$, the outlet temperature of the collector is calculated as:

$T_{\text {out }}=T_{\text {in }}+\frac{G I^{*} A^{*} \eta}{\dot{m} C_{p}}$

where $T_{\text {out }}$ and $T_{\text {in }}$ are, respectively, the outlet and inlet temperature of the collector, $A$ is its area $\left[\mathrm{m}^{2}\right]$, and $\dot{m}$ is the mass flow rate $[\mathrm{kg} / \mathrm{s}]$.

The incidence angle modifier of the solar collector is considered and provided through a data catalog file. Mutual shadowing among collectors, and external shadows due to building structures are considered. A

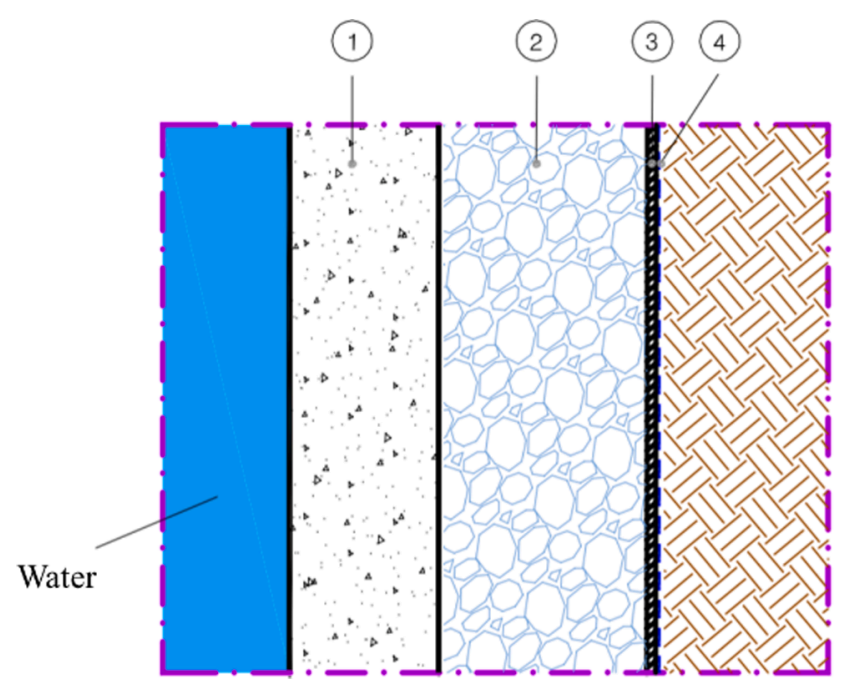

Fig. 5. STES layers: 1) high-density concrete; 2) expanded glass granules; 3) formwork; 4) HDPE vapor barrier. weather data reader (type 15) is used to read the weather data file and transfer information (irradiance, temperature, etc.) to the solar collector. The heat transfer fluid circulates, and is heated up in the solar loop until the temperature is $10{ }^{\circ} \mathrm{C}$ higher than the temperature of the top region of the storage; at this stage the differential controller rules to the three-way valve (type 11f) to divert the flow toward the heat exchanger of the storage. Heat is stored in the STES and delivered to users when required. A gas boiler (type 6) is introduced to supply heat in case the STES is unable to meet demand.

The STES is modelled using type 4, which describes a cylindrical stratified storage tank. The general form of the heat balance equation for thermal energy storage is given in [13] as:

$m C_{p} \frac{d T}{d t}=P_{s}-P_{L}-U S\left(T-T_{a m b}\right)$

where $T$ is the mean temperature of the storage, $P_{s}$ is the rate of energy addition from the solar collector, $P_{L}$ is the rate of energy transferred to the load, $U$ is the heat loss coefficient of the storage envelope, and $S$ is the surface of the STES. The heat loss coefficient depends on both the thickness and thermal conductivity of the storage material, as well as thermal ground resistance.

TRNSYS considers thermal stratification by dividing the overall volume into $N$ fully-mixed volume segments of fluid, and solving the heat balance equation for each volume. Thermal stratification in type 4 is assessed by considering the conductive heat transfer of fluid between adjacent nodes, and variation in internal energy due to the insertion/ extraction of fluid to/ from the STES. Fluid dynamic effects such as buoyancy and jet flow (that destroy stratification by mixing) are not considered. More mathematical details can be found in [37]. An electrical water-water heat pump (HP), modelled using type 927, has been introduced in the model. This type is a performance map: results are a function of a file that contains catalog data regarding the capacity and power that are drawn as a function of load and source temperatures, which are calculated as:

$T_{\text {source,out }}=T_{\text {source, } \text { in }}-\frac{Q_{a b s}}{\dot{m} C_{p}}$

$T_{\text {load, out }}=T_{\text {load,in }}+\frac{\left(Q_{a b s}+P_{\text {heat }}\right)}{\dot{m} C_{p}}$

Where $T_{\text {source,out }}, T_{\text {source, in }}$ are respectively the outlet/inlet source temperature, $T_{\text {load,out }}, T_{\text {load,in }}$ the outlet/inlet load temperature/, $Q_{a b s}$ is the heat rate $[\mathrm{W}]$ absorbed from the source, and $P_{\text {heat }}$ is the electrical work of the heat pump [W].

The aim of the heat pump is to produce heat in efficient way and to lower STES temperature. In general, the performance of SDH components (storage, solar field) strongly depend on the supply and return temperature of the heating plant; in particular, the return temperature $\left(T_{r e t}\right)$ from the net determines the annual minimum temperature of the STES. In this project, the return temperature is quite high (around $50{ }^{\circ} \mathrm{C}$ ), as heat is delivered to dwellings through radiators. As a result, the temperature inside the STES would be limited between 95 and $50^{\circ} \mathrm{C}$. It means that the STES would not be fully discharged from a thermal point of view, significantly reducing its storage capacity. The water-water heat pump overcomes this limitation, as it can extract heat from the STES and allow it to discharge almost totally. In general, it increases the amount of heat produced by renewable energy sources and the solar fraction of the district heating.

The heat pump uses the STES as a source of heat (on the evaporator side), while the user is the sink (condenser side). In the TRNSYS model, it is turned on when the stored heat can no longer be directly exploited for space heating (i.e., when the temperature of the upper region of the storage falls below $T_{U, S}<T_{r e t}+5{ }^{\circ} \mathrm{C}=55^{\circ} \mathrm{C}$ ). If the heat provided by the heat pump is insufficient to meet demand, the backup boiler kicks in. The pump used in our simulations is a commercial product; it is able to 


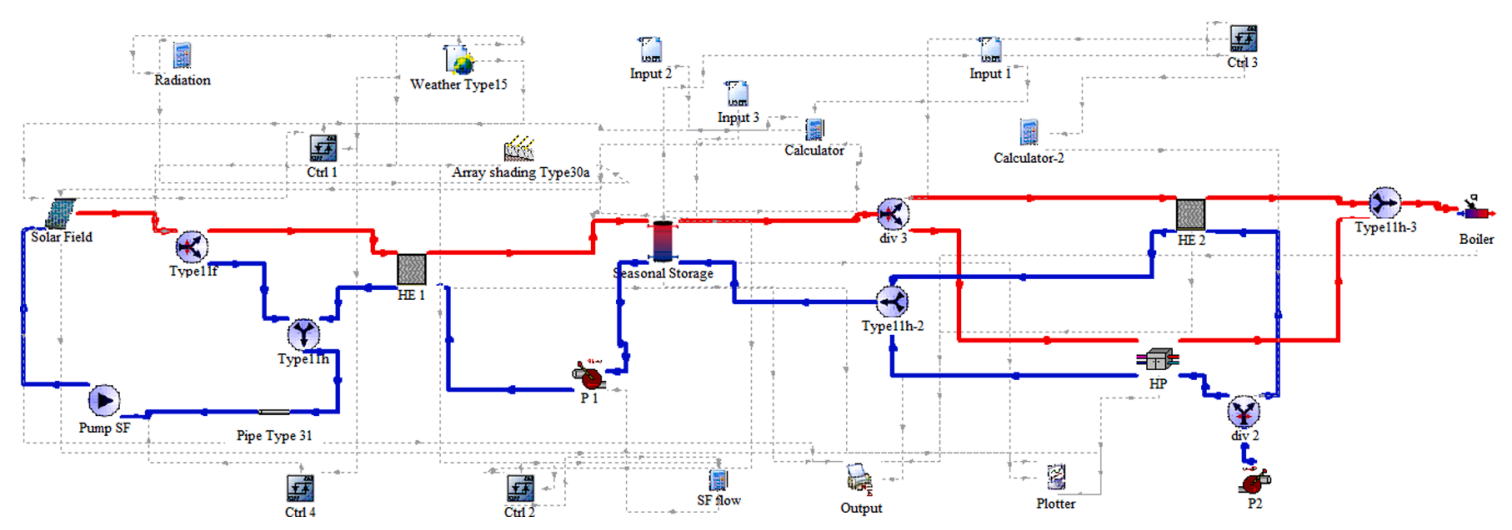

Fig. 6. Overview of the SDH system in TRNSYS.

produce water for space heating and DHW (COP $=4.13$ for $\mathrm{T}_{\mathrm{ev} \text {, in }}=$ $45^{\circ} \mathrm{C}, \mathrm{T}_{\text {con,in }}=70^{\circ} \mathrm{C}, \mathrm{T}_{\text {con,out }}=78^{\circ} \mathrm{C}$ ) and to extract heat from the STES until the temperature falls to $20^{\circ} \mathrm{C}\left(\mathrm{COP}=3.7\right.$ for $\mathrm{T}_{\mathrm{ev} \text {,in }}=20^{\circ} \mathrm{C}, \mathrm{T}_{\text {con,in }}$ $=50{ }^{\circ} \mathrm{C}$, $\mathrm{T}_{\text {con, out }}=65^{\circ} \mathrm{C}$ ) [53].

In order to have a reliable estimation of the heat losses of STES, and determine the optimal thickness of the insulation material a FEM model has been developed with COMSOL Multiphysics ${ }^{\circledR} 5.2$ and integrated into TRNSYS simulations using the iterative procedure described in Section 2.1.

\subsection{The FEM model of the STES}

Our FEM model of the underground tank is a time dependent heat transfer model. It describes the heat transfer between the storage envelope and the soil, taking into account the influence of the external environment (atmosphere) on the heat losses of the STES. In order to reduce the computational cost, exploiting the axial symmetry of the geometry of STES, characterized by truncated cone shape and the axial symmetry of the heat transfer problem, it has been created a 2D axisymmetric geometry. The full 3D solution is obtained by the software rotating the plane of the geometry around the axis of symmetry. The computational domain consists of the storage envelope and the surrounding soil (Fig. 7). The latter extends 70 and $30 \mathrm{~m}$ from the storage in radial and axial directions, respectively. The storage interior, i.e., the water domain, was not modelled, and an analysis of fluid dynamics was not implemented as this requires a full 3D geometry, and the computational effort for a multi-annual simulation would be too high. For simplicity, the domain of the atmosphere is not considered in the model; heat transfer mechanisms between the soil surface and the atmosphere are described by heat transfer correlations.

The energy equation is solved inside the computational domain, following [54], as:

$\rho C_{P} \frac{\partial T}{\partial t}+\nabla \cdot \boldsymbol{q}=\mathrm{R}$

where $\rho$ is the density of the material $\left[\mathrm{kg} / \mathrm{m}^{3}\right], C_{P}$ is the specific heat of the material $\left[\mathrm{J} /\left(\mathrm{kg}^{*} \mathrm{~K}\right)\right], \boldsymbol{q}=-k \nabla T$ is the conductive heat flux $\left[\mathrm{W} / \mathrm{m}^{2}\right]$, in which $k$ is the thermal conductivity of the material $\left[\mathrm{W} /\left(\mathrm{m}^{*} \mathrm{~K}\right)\right]$, and $R$ $\left[\mathrm{W} / \mathrm{m}^{3}\right]$ is a generic thermal source (if present).

The movement of air and moisture in the wall of the STES and the ground are not taken into account to reduce the complexity of the model.

The infinite element domain is used to truncate the computational domain in the radial direction, and avoid effects due to the imposition of boundary conditions (e.g., fixed temperature) that could influence heat transfer. Ground temperature at the boundary of the infinite domain is set at $15^{\circ} \mathrm{C}$. On the bottom boundary of the computational domain, $30 \mathrm{~m}$ below the bottom of the storage, it has been imposed a fixed temperature of $15^{\circ} \mathrm{C}$. The presence of the aquifer ( $12 \mathrm{~m}$ below the soil surface) and its influence on heat transfer is taken into account. The aquifer flows in a gravel layer that is three meters thick and runs a few meters below the bottom of the tank. Due to the 2D axis geometry used in the model, we assume that the aquifer enters the computational domain at a fixed temperature of $15{ }^{\circ} \mathrm{C}$ along the axis of symmetry, and flows radially under the tank. This approach has been considered to be a good approximation of the real situation. Flow in this domain is modelled

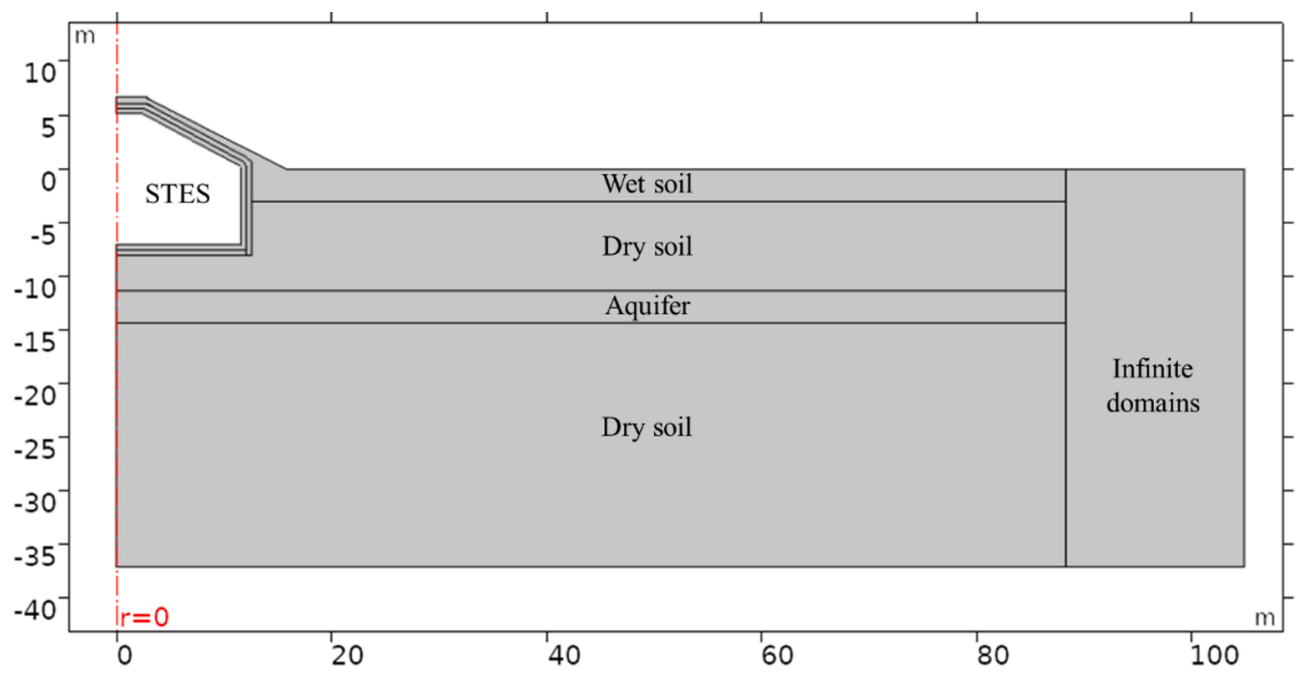

Fig. 7. The computational domain of the model. 
using Darcy's law [55]:

$\boldsymbol{u}=-\frac{\kappa}{\mu} \nabla P$

where $\boldsymbol{u}[\mathrm{m} / \mathrm{s}]$ is the Darcy velocity, $\kappa\left[\mathrm{m}^{2}\right]$ is the permeability of the porous medium, $\mu[\mathrm{Pa} \bullet \mathrm{s}]$ is the dynamic viscosity of the fluid, and $P[\mathrm{~Pa}]$ is fluid pressure. The hydraulic conductivity of the layer is $0.001 \mathrm{~m} / \mathrm{s}$. Fluid flow is characterized by low velocity $\left(|u| \cong 10^{-5}-10^{-6} \mathrm{~m} / \mathrm{s}\right)$.

At the soil surface, several heat transfer mechanisms take place between the ground and the atmosphere. The energy balance is described by the equation:

$-\boldsymbol{n} \cdot \boldsymbol{q}=q_{\text {conv }}+q_{\text {rad }}+q_{a b s}+q_{\text {lat }}$

where $n$ is the normal to the boundary; $q_{\text {conv }}\left[\mathrm{W} / \mathrm{m}^{2}\right]$ represents convective heat transfer between the ground and the atmosphere; $q_{\text {rad }}$ $\left[\mathrm{W} / \mathrm{m}^{2}\right]$ is the radiative heat transfer between the ground and sky; $q_{a b s}\left[\mathrm{~W} / \mathrm{m}^{2}\right]$ describes the absorption of solar irradiance by the soil surface; and $q_{\text {lat }}\left[\mathrm{W} / \mathrm{m}^{2}\right]$ is the heat transfer due to the latent evaporation of ground water. These heat fluxes are applied as boundary conditions to the soil surface.

Heat transfer by convection is described using the equation:

$q_{\text {conv }}=h\left(T_{s}-T_{a m b}\right)$

where $h\left[\mathrm{~W} /\left(\mathrm{m}^{2} * \mathrm{~K}\right)\right]$ is the convective heat transfer coefficient, $T_{s}$ is the soil surface temperature, and $T_{a m b}$ is the ambient temperature. The heat transfer coefficient is calculated using the correlation given in [56] as:

$h=5.6+3.9 v$ for $v<5 m / s(10)$

$h=7.2 v^{0.78}$ for $v>5 \mathrm{~m} / \mathrm{swhere} v$ is the wind velocity module.

Radiative heat transfer between the ground surface and the sky is described using the equation:

$q_{\mathrm{rad}}=\varepsilon_{s} \sigma\left(T_{s}^{4}-T_{s k y}^{4}\right)$

where $T_{s}[\mathrm{~K}]$ is the soil surface temperature; $T_{\text {sky }}[\mathrm{K}]$ is the effective sky temperature; $\sigma=5.67 \cdot 10^{-8} \mathrm{~W} /\left(\mathrm{m}^{2} \mathrm{~K}^{-4}\right)$ is the Stefan-Boltzamnn constant; and $\varepsilon_{s}[-]$ is soil emissivity in the infrared region $(1 \mu \mathrm{m}<\lambda<100$ $\mu \mathrm{m})$. In general, emissivity for various kinds of soil is between 0.9 and 1 [56]; here, it is fixed at $\varepsilon_{s}=0.9$.

To calculate the effective sky temperature the model proposed by $\mathrm{Li}$ et al. [57] has been used. This model considers the radiation emitted by the clouds and thus it is an all sky conditions model:

$T_{s k y}^{4}=\varepsilon_{s k y, c} T_{a m b}^{4}\left(1-a_{1} C F^{a_{2}}\right)+a_{3} T_{a m b}^{4} C F^{a_{4}} \varphi_{a}^{a_{5}}$

where $\varepsilon_{s k y, c}[-]$ is the effective emissivity of the sky for clear sky conditions; $a_{1}, a_{2}, a_{3}, a_{4}$, and $a_{5}$ [-] are the coefficients of the model; $C F$ [\%] is the cloud cover fraction; $\varphi_{a}[\%]$ is relative air humidity. Readers should refer to [57] for the calculation of $\varepsilon_{s k y, c}$ and values of coefficients $a_{1} . . a_{5}$.

Latent evaporation energy is calculated using the correlation [56]:

$q_{\text {lat }}=0.0168 h\left(\varphi_{s} p_{s}-\varphi_{a} p_{a}\right)$

where 0.0168 has dimensions $\left[\frac{K}{P a}\right], h\left[\mathrm{~W} /\left(\mathrm{m}^{2 *} \mathrm{~K}\right)\right]$ is the convective heat transfer coefficient, $\varphi_{s}[\%]$ and $\varphi_{a}[\%]$ are the relative humidity of the soil surface and the air, and $p_{s}[\mathrm{~Pa}]$ and $p_{a}[\mathrm{~Pa}]$ are the water vapor pressure at the soil surface and of air. Details of the calculation of $\varphi_{s}, p_{s}, p_{a}$ can be found in [56].

Finally, it has been considered the absorption of the solar irradiance by the soil surface:

$q_{a b s}=\alpha_{s} G H I$

where $\alpha_{s}[-]$ is the ground absorption coefficient in the solar spectrum $(0.3 \mu \mathrm{m}<\lambda<2.5 \mu \mathrm{m})$ and $G H I\left[\mathrm{~W} / \mathrm{m}^{2}\right]$ is global horizontal irradiance. In cases where the soil surface slopes, irradiance is projected.

Annual hourly profiles of ambient temperature, wind velocity, global horizontal radiation, air humidity and cloud cover fraction for Florence [44] have been employed in the model.

The main physical properties of the materials used in the FEM model are reported in Table 10 . The ground is mostly composed of silt loam (sand $20.4 \%$, silt $53.7 \%$, clay $25.9 \%$ ), established through a soil analysis. It has been verified that gravimetric water is limited to the first three meters and does not exceed $20 \%$. Therefore, the computational soil domain is divided into two regions (Fig. 7): the first describes conditions up to three meters below the surface, which is characterized by wet soil; the second, from $3 \mathrm{~m}$ of depth to $35 \mathrm{~m}$, is characterized by dry soil. The relation between thermal conductivity and specific heat on soil temperature is neglected.

Thermal conductivity of the insulation material (expanded glass granules for the sides and top, foam glass for the bottom) is set at $k=$ $0.08 \mathrm{~W} /(\mathrm{m} * \mathrm{~K})$ at ambient temperature and $k=0.09 \mathrm{~W} /(\mathrm{m} * \mathrm{~K})$ at $90{ }^{\circ} \mathrm{C}$ [51].

The numerical grid is composed of a mesh of 68,000 elements; finer elements are used for the walls to accurately calculate thermal fluxes and obtain the temperature distribution, while coarser elements are implemented for ground far away from the storage. The time step is fixed at one hour. This is justified by the fact that inputs to simulations are provided as hourly data (storage temperature, ambient temperature, global irradiance, etc.) and because the temperature of the storage and of the ground changes slowly $\left(\frac{d T}{d t}<0.1^{\circ} \mathrm{C} /\right.$ hour $)$. The time period is set to 10 years, in order to obtain stable results for soil temperature surrounding the storage.

\section{Results}

\subsection{STES heat loss}

Three configurations with different widths of the insulation layer $(30 \mathrm{~cm}, 50 \mathrm{~cm}, 70 \mathrm{~cm})$ for a storage volume of $3800 \mathrm{~m}^{3}$ were investigated. We assume that the width of the insulation layer is uniform, i.e., it is the same for the bottom, sides, and top.

Fig. 8 is a $2 \mathrm{D}$ plot of the temperature field of the storage system and the surrounding ground with $70 \mathrm{~cm}$ of insulation for one hour in the fourth year of operation, during the fall when the storage is discharging to release heat to users. Arrows indicate the direction and strength of the heat flux. This figure highlights that heat inside the storage system heats up the surrounding soil. The insulation material is hotter in bottom compared to top regions, since it is less influenced by the external temperature. The aquifer, at around $12 \mathrm{~m}$ below the soil surface, aborbs some of the heat. As expected, heat flux is highest in ground layers closer to the surface.

Simulated heat losses are reported in Table 11, divided into bottom, side and top losses. Predicted losses with $30 \mathrm{~cm}$ insulation are estimated to be around $83 \mathrm{MWh} / \mathrm{yr}$. For $70 \mathrm{~cm}$ insulation thickness, a reduction of the heat losses of about $30 \mathrm{MWh} / \mathrm{yr}$ is expected. Most losses, around $45 \%$ of the total for 30 and $50 \mathrm{~cm}$, and $42 \%$ for $70 \mathrm{~cm}$, are from the top regions. With $\mathrm{V}=3800 \mathrm{~m}^{3}, \mathrm{~S}=1452 \mathrm{~m}^{2}$, the temperature during the STES cycle is $T_{\max }=90^{\circ} \mathrm{C}, T_{\min }=25^{\circ} \mathrm{C}$, and $T_{a m b}=15^{\circ} \mathrm{C}$; the average heat transfer coefficient with $70 \mathrm{~cm}$ of insulation is $\mathrm{U}=0.10 \mathrm{~W} /\left(\mathrm{m}^{2 *} \mathrm{~K}\right)$.

It should be noted that these results could still underestimate heat losses. Several minor heat transfer mechanisms, such as natural convection in the water in the STES, natural convection in the air in the top levels of the system, the diffusion of water vapor within the layers, and

Table 10

Properties of materials used in the FEM model at $T=20^{\circ} \mathrm{C}$.

\begin{tabular}{llll}
\hline Materials & $\boldsymbol{\rho}\left[\mathbf{k g} / \mathbf{m}^{3}\right]$ & $\mathbf{k}[\mathrm{W} /(\mathbf{m} * \mathbf{K})]$ & $\mathbf{C}_{\mathbf{p}}\left[\mathbf{J} /\left(\mathbf{k g}{ }^{*} \mathbf{K}\right)\right]$ \\
\hline High density concrete [58] & 2400 & 2.3 & 1000 \\
Expanded glass granules [59] & 160 & 0.08 & 850 \\
Dry soil & 1550 & 0.65 & 1000 \\
Wet soil (20\%) & 1890 & 0.9 & 1540 \\
\hline
\end{tabular}




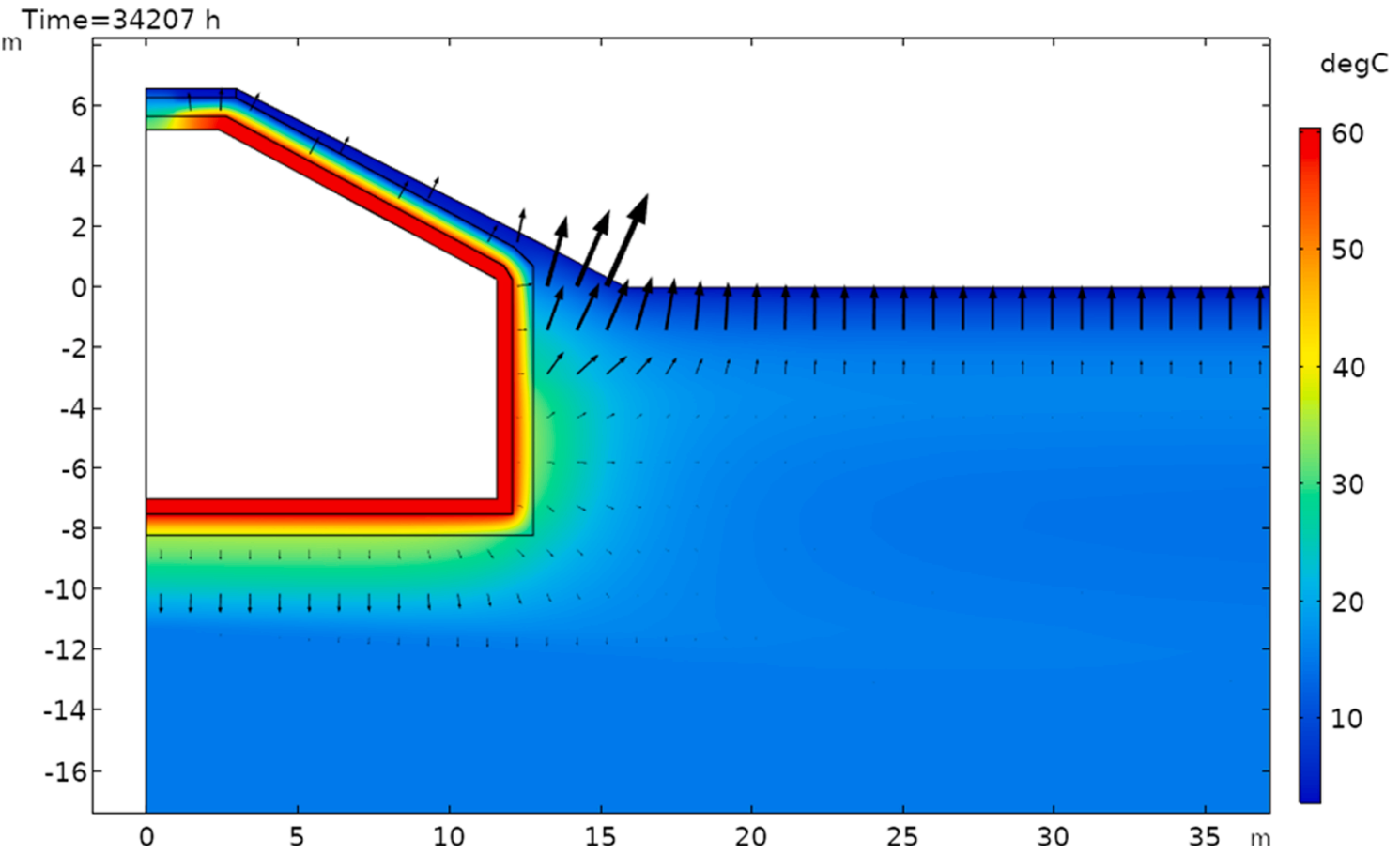

Fig. 8. Temperature field of the storage system and the surrounding ground.

Table 11

Results of FEM simulations for various thickness of the insulation layer.

\begin{tabular}{lllll}
\hline $\begin{array}{l}\text { Insulation } \\
\text { thickness [cm] }\end{array}$ & $\begin{array}{l}\text { Heat losses } \\
{[\text { MWh/yr] }}\end{array}$ & $\begin{array}{l}\text { Bottom } \\
\text { losses } \\
{[\mathbf{M W h} / \mathbf{y r}]}\end{array}$ & $\begin{array}{l}\text { Side losses } \\
{[\mathrm{MWh} / \mathrm{yr}]}\end{array}$ & $\begin{array}{l}\text { Top losses } \\
{[\mathbf{M W h} / \mathbf{y r}]}\end{array}$ \\
\hline 30 & 83 & 18 & 27 & 37 \\
50 & 69 & 15 & 23 & 31 \\
70 & 53 & 13 & 18 & 22 \\
\hline
\end{tabular}

the diffusion of water in the soil are not considered in order to reduce the computational cost. However, their contribution to total heat losses can be neglected.

A more important contribution to losses may be moisture penetration into the insulation material. Many STES projects have faced this problem, due to the failure of the vapor barrier used to protect the insulation. Thermal conductivity of expanded glass granules increases rapidly with moisture content [60]: for instance, with $20 \%$ of volumetric water content and $80^{\circ} \mathrm{C}$, it increases by a factor of 10 compared to the value of the dry insulator. For this reason, FEM simulations have been run to evaluate the effect of moisture content on heat losses for three insulation thicknesses $(30 \mathrm{~cm}, 50 \mathrm{~cm}, 70 \mathrm{~cm})$ in the worst-case scenario (i.e., $20 \mathrm{vol}$ $\%$ of water content). The thermal conductivity trend with temperature used in simulation for $20 \mathrm{vol} \%$ of water content is described by the exponential relation: $0.1003^{*} \mathrm{e}^{\left(0.0247^{*} \mathrm{~T}\left[{ }^{\circ} \mathrm{C}\right]\right)}$, obtained from [51] for $T>$ $0{ }^{\circ} \mathrm{C}$. Variation in density and the specific heat of the insulation material with increased moisture content is calculated following [61] as:

$\rho_{w e t}=\rho_{d r y}+\rho_{w} w$

$c_{w e t}=\frac{\rho_{d r y} c_{d r y}+\rho_{w} c_{w} w}{\rho_{d r y}+\rho_{w} w}$

where $\rho_{\text {wet }}, \rho_{\text {dry }}$, and $\rho_{w}$ are, respectively, the density of wet and dry material, and water density $\left[\mathrm{kg} / \mathrm{m}^{3}\right] ; w$ is moisture content by volume; and $c_{w e t}, c_{d r y}, c_{w}$ are, respectively, the specific heat of wet material, dry material and water $[\mathrm{W} /(\mathrm{m} * \mathrm{~K})]$. The results are reported in Table 12.

Table 12 highlights that heat losses in the wet condition are, at a minimum, doubled compared to the dry condition. Growth is higher in
Table 12

STES heat losses for various thickness of insulation and $20 \%$ volumetric water content.

\begin{tabular}{lllll}
\hline $\begin{array}{l}\text { Insulation } \\
\text { thickness [cm] }\end{array}$ & $\begin{array}{l}\text { Heat Losses } \\
{[\text { MWh/yr] }}\end{array}$ & $\begin{array}{l}\text { Bottom } \\
\text { Losses } \\
{[\text { MWh/yr] }}\end{array}$ & $\begin{array}{l}\text { Side Losses } \\
{[\text { [MWh/yr] }}\end{array}$ & $\begin{array}{l}\text { Top Losses } \\
{[\text { MWh/yr] }}\end{array}$ \\
\hline 30 & 174 & 30 & 50 & 94 \\
50 & 160 & 30 & 47 & 83 \\
70 & 137 & 27 & 42 & 68 \\
\hline
\end{tabular}

the top regions where heat transfer is stronger. A $30 \mathrm{~cm}$ insulation layer is characterized by $174 \mathrm{MWh}$ annual heat loss. Given that the preliminary TRNSYS simulation estimated heat production in the solar field of around $800 \mathrm{MWh}$, it appears that around $22 \%$ of the heat that is collected could be lost in storage. With $70 \mathrm{~cm}$ insulation, even with moisture penetration, these losses could be limited to around $17 \%$.

As noted in Section 2.5, experimental heat loss in European STES is substantially higher than predicted values. Even if the analysis reported here is more reliable, thanks to the use of the FEM model, many unpredicted problems can arise during the operations of the storage (notably moisture penetration) despite a careful design and realization. Therefore, following the comparison of heat losses with dry and wet insulation, it has been selected $70 \mathrm{~cm}$ as the minimum insulation thickness for this project.

To improve TRNSYS simulations, and provide a conservative estimate of heat produced by solar technologies, the heat transfer coefficient obtained from the simulation with $70 \mathrm{~cm}$ dry insulation has been multiplied by a safety factor of 1.8. Thus, a heat transfer coefficient of $\mathrm{U}$ $=0.18 \mathrm{~W} /\left(\mathrm{m}^{2} \mathrm{~K}\right)$ is used in the TRNSYS model.

\subsection{Parametric analysis}

The main parameters used in TRNSYS simulations are reported in Table 13.

Drawing on information derived from the FEM model, we ran a parametric analysis in TRNSYS. Here, the aim was to vary the storage volume while keeping the surface of the solar field fixed at $1000 \mathrm{~m}^{2}$ 
Table 13

Types used in TRNSYS simulations and the main boundary conditions.

\begin{tabular}{|c|c|}
\hline Component & Relevant parameter \\
\hline Thermal Storage (type 4) & $\begin{array}{l}\mathrm{U}=0.18 \mathrm{~W} /\left(\mathrm{m}^{2} \mathrm{~K}\right) \\
\mathrm{H}=9.8 \mathrm{~m} \\
1500 \mathrm{~m}^{3}<\text { Volume }<6000 \mathrm{~m}^{3} 10 \\
\text { temperature nodes }\end{array}$ \\
\hline Evacuated solar collector (type 71) & $\begin{array}{l}\text { Net area of the solar field }=1000 \\
\mathrm{~m}^{2} \\
\eta 0=0.641, \mathrm{c} 1=0.935 \mathrm{~W} /\left(\mathrm{m}^{2} \mathrm{~K}\right) \\
\mathrm{c} 2=0.004 \mathrm{~W} /\left(\mathrm{m}^{2} \mathrm{~K}^{2}\right) \\
\text { Collector gross area: } 3.86 \mathrm{~m}^{2} \\
\text { Flow rate: } 0.02 \mathrm{~kg} /\left(\mathrm{m}^{2} \mathrm{~s}\right)\end{array}$ \\
\hline Water-water heat pump (type 927) & $\begin{array}{l}\text { Heating capacity } 279 \mathrm{KW} \\
\text { Power } 67.6 \mathrm{~kW} \\
\text { COP } 4.13 \\
\text { Operational if } 20{ }^{\circ} \mathrm{C}<\mathrm{T}_{\mathrm{ev} \text {,in }}< \\
45^{\circ} \mathrm{C}\end{array}$ \\
\hline Differential controller (type $2 b$ ) & $\begin{array}{l}\text { Operating condition of the solar } \\
\text { field: } \\
\text { On if GHI }>150 \mathrm{~W} / \mathrm{m}^{2} \\
\text { Controlling heat transfer between } \\
\text { solar field/STES: } \\
\text { Transfer heat to STES if } \mathrm{T}_{\text {out }}>\mathrm{T}_{\mathrm{U}} \text {, } \\
\mathrm{s}+10^{\circ} \mathrm{C} \\
\text { Controlling heat transfer between } \\
\text { STES/users: } \\
\text { Transfer heat directly from STES } \\
\text { if } \mathrm{T}_{\mathrm{U}, \mathrm{S}}>55^{\circ} \mathrm{C} \\
\text { Use heat pump if } \mathrm{T}_{\mathrm{U}, \mathrm{S}}<55^{\circ} \mathrm{C}\end{array}$ \\
\hline $\begin{array}{l}\text { Heat exchanger with hot side bypass (type } 650 \text { ) } \\
\text { to keep the cold side outlet below a } \\
\text { temperature setpoint }\end{array}$ & $\begin{array}{l}\text { Solar field/STES HX } \mathrm{T}_{\text {setpoint }}= \\
95^{\circ} \mathrm{C} \\
\text { STES/User } \mathrm{T}_{\text {setpoint }}=66^{\circ} \mathrm{C}\end{array}$ \\
\hline Details of the TRNSYS simulation & $\begin{array}{l}\text { Time step }=5 \mathrm{~min} \\
\text { Simulation period }=3 \text { years } \\
\text { Supply/return temperature to } \\
\text { users } 66 / 50^{\circ} \mathrm{C}\end{array}$ \\
\hline
\end{tabular}

(equal to the maximum number of collectors that can be installed). The simulation period was set at three years, in order to model stable conditions. The simulation time step was set at five minutes. A sample of the results is reported in Table 14. It is worth to note that the heat collected by the solar field does not match with heat delivered to the STES system. This is due to losses in pipework, and the efficiency of the heat exchanger that connects the solar field to the STES.

Table 14 highlights that smaller volume STES (1500 and $2500 \mathrm{~m}^{3}$ ) cannot provide a solar fraction above $40 \%$, since STES capacity is small and is fully charged at the beginning of summer season. However, larger volumes, with bigger storage capacity have a solar fraction of up to $44-45 \%$. The amount of useful heat delivered to users increases somewhat, from $3800 \mathrm{~m}^{3}$ to $5000 \mathrm{~m}^{3}$ (only $15 \mathrm{MWh}$ ). This is due to the suboptimal STES aspect ratio, which increases heat losses even though the mean STES temperature falls. As volume increases up to $6000 \mathrm{~m}^{3}$ there are no further advantages in terms of delivered heat to users. Consequently, since the solar field net aperture area and the height of the STES are fixed, due to external constraints, there are no advantages to building a volume bigger than $4000 \mathrm{~m}^{3}$ as the net heat delivered to users does not change significantly. Thus, from the economic point of

Table 14

Results of TRNSYS simulations for different STES volumes.

\begin{tabular}{llllll}
\hline $\begin{array}{l}\text { Volume } \\
{\left[\mathrm{m}^{3}\right]}\end{array}$ & $\begin{array}{l}\text { SF } \\
\text { production } \\
{[\text { MWh] }}\end{array}$ & $\begin{array}{l}\text { STES } \\
\text { Losses } \\
{[\text { MWh }]}\end{array}$ & $\begin{array}{l}\text { Heat from } \\
\text { STES to } \\
\text { user } \\
{[\text { MWh] }}\end{array}$ & $\begin{array}{l}\text { STES } \\
\mathbf{T}_{\max } \\
{\left[{ }^{\circ} \mathbf{C}\right]}\end{array}$ & $\begin{array}{l}\text { Solar } \\
\text { Fraction } \\
{[\%]}\end{array}$ \\
\hline 1500 & 625 & 50 & 554 & 94 & 36 \\
2500 & 701 & 69 & 609 & 94 & 40 \\
3800 & 780 & 90 & 668 & 92 & 44 \\
5000 & 808 & 105 & 682 & 82 & 45 \\
6000 & 818 & 115 & 684 & 73 & 45 \\
\hline
\end{tabular}

view the additional costs of excavation and materials are not justified.

A size of $3800 \mathrm{~m}^{3}$ has been selected as the optimal STES volume for the Florence project, which is a trade-off between energetic performance and cost. The solar fraction expected for this configuration is $44 \%$. The detailed heat balance for a plant with a STES volume of $3800 \mathrm{~m}^{3}$ is reported in Table 15. Total heat demand for the buildings includes all losses due to distribution and generation.

STES efficiency, defined as the ratio of the energy provided by the storage to the total thermal energy input, is $88 \%$. Furthermore, in the scenario with dry insulation material, $U=0.10 \mathrm{~W} /\left(\mathrm{m}^{2 *} \mathrm{~K}\right)$, STES heat losses are halved, and the solar fraction increases to $45 \%$ for $\mathrm{V}=3800$ $\mathrm{m}^{3}$.

It should be noted that the integration of the heat pump into the system remarkably increases the solar fraction compared to the configuration without it; a comparison of the two configurations is reported in Table 16. Following an analysis of the hourly heat load of the two buildings, the size of the heat pump has been set at $279 \mathrm{~kW}$. With a STES volume of $3800 \mathrm{~m}^{3}$ and the installation of the heat pump, the useful heat extracted from the system increases to $133 \mathrm{MWh}(25 \%)$, and the solar fraction increases from $35 \%$ to $44 \%$. This is due to the increased STES capacity and a reduction in heat losses due to the low average temperature. In comparison, for a system without a heat pump, storage capacity is limited to $181 \mathrm{MWh}$ (due to the temperature interval $51 / 92{ }^{\circ} \mathrm{C}$. With the heat pump, the minimum temperature drops to $23^{\circ} \mathrm{C}$ and capacity increases to $305 \mathrm{MWh}$ (124 MWh more). Similarly, in the configuration with the heat pump, storage is discharged to $84 \%$ of its ideal capacity (assuming $\mathrm{T}_{\min }=10{ }^{\circ} \mathrm{C}, \mathrm{T}_{\max }=92^{\circ} \mathrm{C}$ ), while without it, it is only discharged to $50 \%$.

Furthermore, it should be noted that selecting a heat pump with better performance could lower the minimum storage temperature to $10{ }^{\circ} \mathrm{C}$ and consequently further increase the solar fraction.

Fig. 9 shows annual variation in mean STES temperature. This figure illustrates the different operating conditions of the SDH system during the course of a year, and the control strategies that have been established thanks to the TRNSYS model. At the end of the space heating season (i.e., the beginning of spring, $t=2200$ ), the STES is fully discharged (to the limit of the selected heat pump) with respect to temperature; during this period, solar resources start to increase and the solar field starts to transfer heat to the storage volume. Since heat demand is low, and limited to DHW, the storage temperature rises. Charging continues during summer time when irradiation from the Sun is higher. At the end of the summer, the storage volume is fully charged, reaching a maximum temperature of $92^{\circ} \mathrm{C}$. In fall, user demand grows as space heating is turned on; the STES begins to discharge to provide direct heat. This process continues as long as the STES maximum temperature is higher than the return temperature. As the temperature of the STES becomes closer to the return temperature, the heat pump is switched on. The heat pump extracts heat from the STES, discharges the storage volume and delivers heat to the user. If demand exceeds the heat provided by the heat pump, the back-up boilers are switched on. The heat pump is in use from December to March. At the end of winter the

Table 15

Heat balance of the plant. Storage volume of $3,800 \mathrm{~m}^{3}$.

\begin{tabular}{ll}
\hline & [MWh/yr] \\
\hline Total heat demand & 1522 \\
Heat collected by the solar field & 780 \\
STES balance: & \\
- Heat input from the solar field & 758 \\
- STES losses & 90 \\
- Heat output directly to user & 356 \\
- Extracted from the heat pump & 312 \\
Heat to user from: & \\
- Gas boiler & 770 \\
- STES directly & 356 \\
- STES + heat pump & 396 \\
\hline
\end{tabular}


Table 16

Comparison of performance with and without the heat pump for a STES volume of $3800 \mathrm{~m}^{3}$.

\begin{tabular}{lllll}
\hline HP & $\begin{array}{l}\text { SF production } \\
{[\mathrm{MWh} / \mathrm{yr}]}\end{array}$ & $\begin{array}{l}\text { Heat from STES to } \\
\text { user }[\mathrm{MWh} / \mathrm{yr}]\end{array}$ & $\begin{array}{l}\text { STES } \mathrm{T}_{\min } \\
{\left[{ }^{\circ} \mathbf{C}\right]}\end{array}$ & $\begin{array}{l}\text { Solar } \\
\text { Fraction [\%] }\end{array}$ \\
\hline No & 686 & 535 & 51 & 35 \\
Yes & 780 & 668 & 23 & 44 \\
\hline
\end{tabular}

cycle ends.

Fig. 10 reports annual heat demand profiles for the different heat sources (the STES, the heat pump, and the boiler) and the solar fraction of the SDH. This figure illustrates that renewable sources can fully satisfy heat demand during the summer months. Around half of the heat stocked is used directly in November and December, and the other half is extracted by the heat pump in the other winter months. The monthly solar fraction of the SDH reaches its minimum in February (21\%) and maximum in the summer months. The value in May decreases sharply compared to April as the heat pump is turned off and the mean storage temperature cannot meet heat demand.

Fig. 11 shows global radiation available on the collectors, the heat produced by the solar field and the efficiency of the collectors. This shows that efficiency is higher in spring when the storage is discharged and the working temperature of the solar field is lower. In summer, efficiency decreases due to the high working temperature and the fact that the part of the radiation is not exploited, as the storage is fully charged (especially in August).

For what concerns the thermal stratification of the storage, it has been supposed in TRNSYS simulations that hot water from the solar field enters the tank close to the top of the volume, and cold water from users enters at the bottom; in turn, cold water is supplied to the solar field from the bottom of the tank, and users are supplied with hot water from the top. Regardless of the strategy, the thermal stratification predicted is quite poor, reflected in a $10{ }^{\circ} \mathrm{C}$ difference between the top and the bottom of the volume. This is due to the height to diameter ratio, which

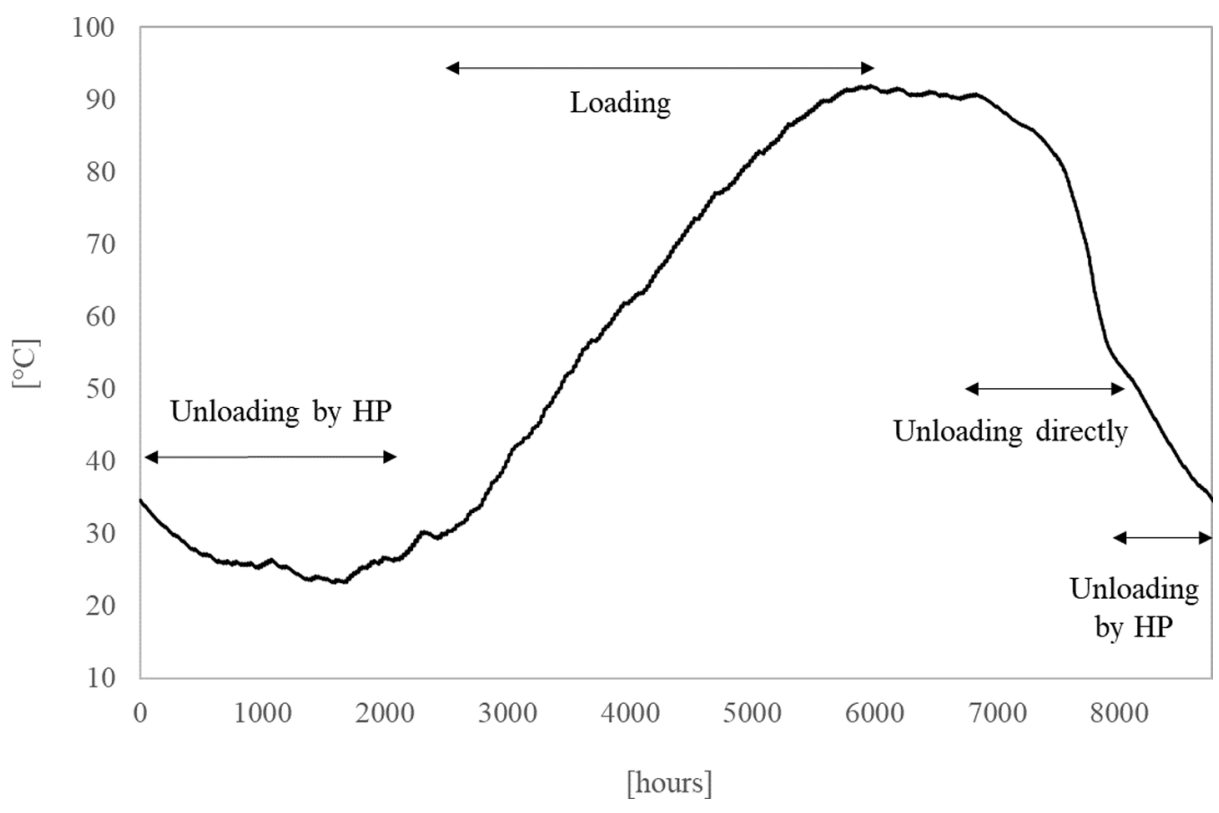

Fig. 9. Annual mean temperature profile inside the STES.

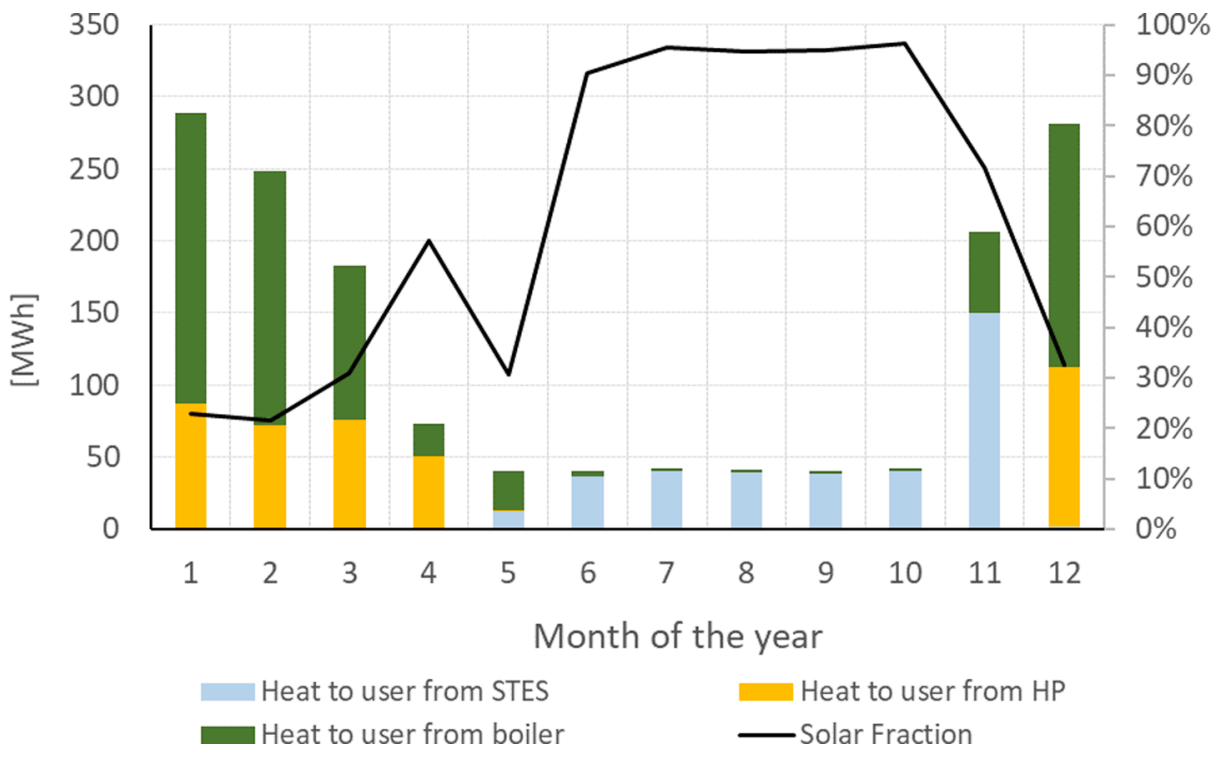

Fig. 10. Annual profile of SDH heat demand. 


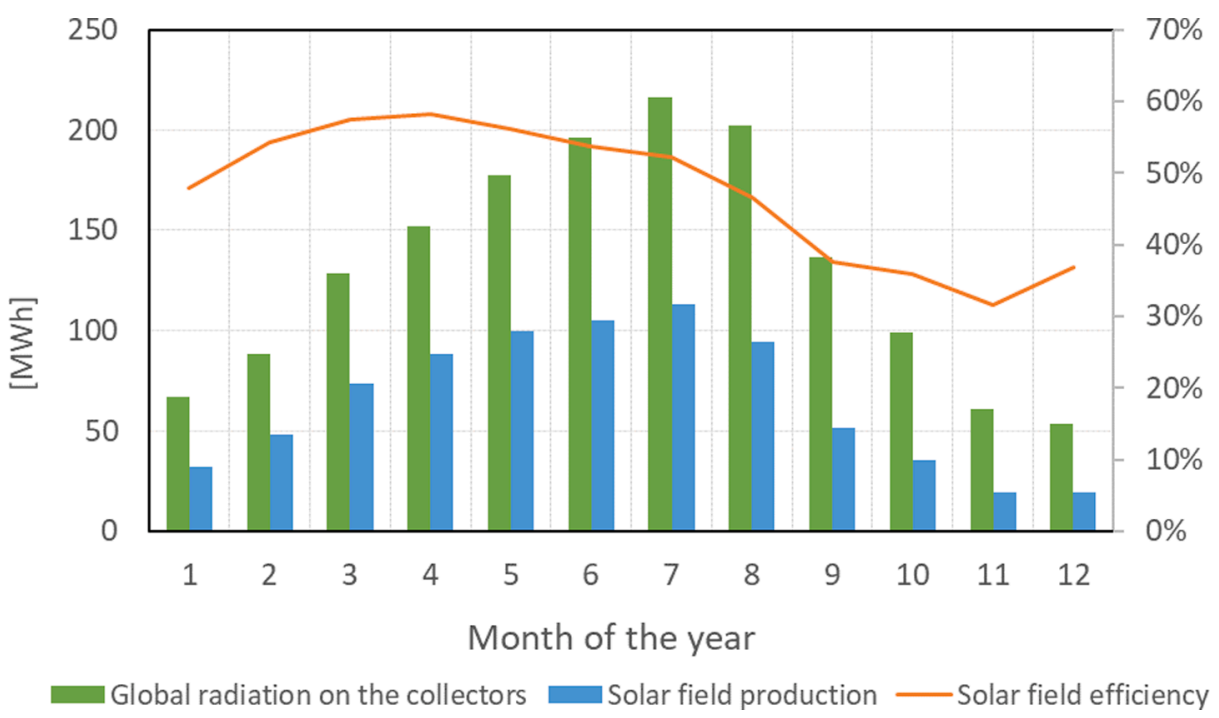

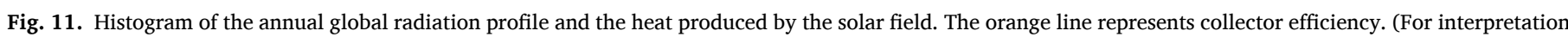
of the references to colour in this figure legend, the reader is referred to the web version of this article.)

does not promote stratification.

Therefore, a new charge and discharge solution is needed to increase stratification. An approach has already been designed and will be implemented in the tank. Specifically, the typical storage configuration, which is characterized by four inlet/ outlet ports (two at the bottom and two at the top of the tank) will be modified. As noted above, the classic configuration is characterized by two levels of charge and discharge: water supplied to the solar field, at lower temperature, is drawn from the bottom of the STES, and returning water, at higher temperature, is introduced at the top; users are supplied with water at higher temperature from the top of the tank and the returning water, which is at a lower temperature, is injected at the bottom. In many situations, this configuration forces water at different temperatures to mix, causing the destruction of exergy. For instance, on days with poor irradiation, the water flowing in the solar field would not reach the temperature of the top of the STES and so, the insertion of colder water returning from the solar field would lower the temperature level of the top layers. Adding another, intermediate-level port at a height where the temperature is lower compared to the top of the STES partly fixes this problem, as it allows flow from the solar field to be discharged in a region of the STES that is characterized by lower temperatures.

The new solution implemented in the Florence project foresees a sixport configuration (three for charging and three for discharging). These ports will be placed at different heights (top, bottom and middle). Through the use of electronic valves, all the hydraulic circuits (the solar field loop, the user loop, and the heat pump loop) will be connected to each of them. Thus, each circuit has six connections with the STES (18 connections in total), and can draw and inject water at three levels. Compared to the classical configuration, there are two more levels of charge and discharge for each circuit. This configuration makes it possible to insert (extract) water in the storage region where the temperature is closest to that of the incoming (outgoing) water, in order to avoid the mixing of fluids at different temperatures and exergy destruction.

This system increases thermal stratification and available heat. The layout of the internal piping, showing the different levels of charge and discharge for one hydraulic circuit, is reported in Fig. 12. Numerical simulations in TRNSYS estimate the rise of the solar fraction of $1 \%$ more,

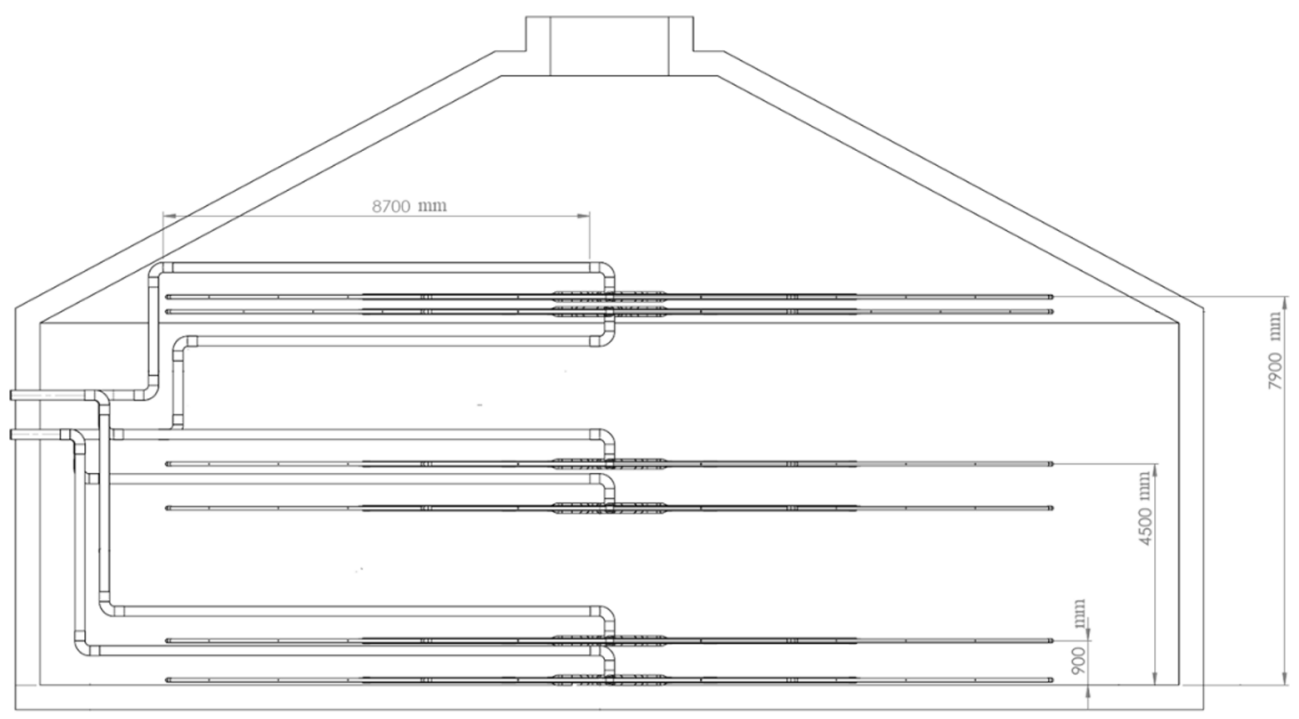

Fig. 12. Layout of the internal piping. 
up to $45 \%$ due to this new layout.

\section{Conclusions}

The concept of solar district heating associated with a seasonal thermal energy storage is a promising strategy to reduce the consumption of fossil fuels by households. It has been widely applied in Northern European countries (Sweden, Denmark, and Germany) but not, until now, in Italy. A new project will be implemented in Florence, under the European REPLICATE project, which is financed under the Horizon 2020 Smart Cities and Communities program. The SDH will be built in a residential area as an improvement to two social housing (299 dwellings) buildings, which will also be made more energy efficient. This paper presents an innovative numerical approach to the design of the heating plant. For the first time, the design phase is based on the coupling of a dynamic SDH model (in TRNSYS) and a FEM model of the STES. The aim is to obtain a more detailed analysis, and a more reliable estimation of performance. The two models are linked via the temperature profile of the storage volume.

The key results of our study are as follows:

The inclusion of the FEM model makes it possible to calculate heat losses for different insulation thicknesses and moisture content, and determine the optimal insulation thickness $(70 \mathrm{~cm}$ of expanded glass granules).

A parametric analysis of the TRNSYS model determined the optimal size of the solar field and the storage volume. The solar field net aperture area is set at $1000 \mathrm{~m}^{2}$. A volume of $3800 \mathrm{~m}^{3}$ for the STES water tank is considered to be the best trade-off between energetic performance and costs.

We obtained a reliable estimation of the solar fraction of the SDH plant: $44 \%$.

The TRNSYS model demonstrated that the water-water heat pump is a key component in the project, and considerably improves system performance. The temperature interval for the annual STES cycle with the heat pump is $92 / 23^{\circ} \mathrm{C}$.

Control strategies for the heating plant were determined based on the maximization of the solar fraction and optimizing STES performance.

It is expected to validate the TRNSYS-FEM model with future experimental results.

The project demonstrates that even in urban environments that are characterized by limited space, it is possible to integrate renewable energy solutions. This technology has huge potential and, given the weight of the residential sector in energy consumption, its implementation is crucial. Novel numerical methods, as presented in this paper, are a mandatory step in the careful design of SDH.

\section{Declaration of Competing Interest}

The authors declare that they have no known competing financial interests or personal relationships that could have appeared to influence the work reported in this paper.

\section{References}

[1] International Energy Agency (IEA), Transition to sustainable buildings: Strategie and opportunities to 2050, Oecd. 9789264202955 (2013) 1-284. https://doi.org/ 10.1787/9789264202955-en.

[2] K. Kavvadias, J.P. Jiménez-Navarro, G. Thomassen, Decarbonising the EU heating sector, EUR 29772 EN, Publ. Off. Eur. Union. (2019). https://www.doi.org/ 10.2760/943257 (accessed 06 July 2021).

[3] Eurostat, EU statistics 2019. https://ec.europa.eu/eurostat/statistics-explained/ index.php/Energy consumption in households (accessed 06 July 2021).

[4] S. Tsemekidi Tzeiranaki, P. Bertoldi, F. Diluiso, L. Castellazzi, M. Economidou, N. Labanca, T. Ribeiro Serrenho, P. Zangheri, Analysis of the EU residential energy consumption: Trends and determinants, Energies 12 (6) (2019) 1065, https://doi. org/10.3390/en12061065.

[5] Eurostat, EU statistics 2019. https://ec.europa.eu/energy/topics/energyefficiency/heating-and-cooling_en (accessed 06 July 2021).
[6] A. Jäger-Waldau, PV Status Report 2019, 2019. https://doi.org/10.2760/326629 (accessed 06 July 2021).

[7] M.A. Sayegh, J. Danielewicz, T. Nannou, M. Miniewicz, P. Jadwiszczak, K. Piekarska, H. Jouhara, Trends of European research and development in district heating technologies, Renew. Sustain. Energy Rev. 68 (2017) 1183-1192, https:// doi.org/10.1016/j.rser.2016.02.023.

[8] European Commission's Directorates-General for Research and Innovation, Joint Research Centre. Set-Plan Action $N^{\circ} 3.2$ Implementation Plan; European Commission: Brussels, Belgium, 2018.

[9] D. Tschopp, Z. Tian, M. Berberich, J. Fan, B. Perers, S. Furbo, Large-scale solar thermal systems in leading countries: A review and comparative study of Denmark, China, Germany and Austria, Appl. Energy. 270 (2020) 114997, https://doi.org/ 10.1016/j.apenergy.2020.114997.

[10] Eurostat, Energy from renewables sources, EU statistics 2019. https://ec.europa eu/eurostat/web/energy/data/shares (accessed 06 July 2021).

[11] A. Dahash, F. Ochs, M.B. Janetti, W. Streicher, Advances in seasonal thermal energy storage for solar district heating applications: A critical review on largescale hot-water tank and pit thermal energy storage systems, Appl. Energy. 239 (2019) 296-315, https://doi.org/10.1016/j.apenergy.2019.01.189.

[12] L.F. Cabeza, Advances in Thermal Energy Storage Systems: Methods and Applications, Elsevier (2014), https://doi.org/10.1016/C2013-0-16453-7.

[13] J.A. Duffie, W.A. Beckman, J. McGowan, Solar Engineering of Thermal Processes, John Wiley \& Sons 53 (4) (1985) 382, https://doi.org/10.1119/1.14178.

[14] IEA, Seasonal thermal energy storage - Report on state of the art and necessary further R + D, IEA-SHC Task 45 Large Syst. (2015) 1-48. http://task45.iea-shc. org/data/sites/1/publications/IEA_SHC_Task45_B_Report.pdf (accessed 06 July 2021).

[15] C. Bott, I. Dressel, P. Bayer, State-of-technology review of water-based closed seasonal thermal energy storage systems, Renew. Sustain. Energy Rev. 113 (2019) 109241, https://doi.org/10.1016/j.rser.2019.06.048.

[16] J. Xu, R.Z. Wang, Y. Li, A review of available technologies for seasonal thermal energy storage, Sol. Energy. 103 (2014) 610-638, https://doi.org/10.1016/j. solener.2013.06.006.

[17] A. Hesaraki, S. Holmberg, F. Haghighat, Seasonal thermal energy storage with heat pumps and low temperatures in building projects - A comparative review, Renew. Sustain. Energy Rev. 43 (2015) 1199-1213, https://doi.org/10.1016/j. rser.2014.12.002

[18] J.-O. Dalenbäck, T. Jilar, Swedish solar heating with seasonal storage -design, performance and economy, Int. J. Ambient Energy. 6 (3) (1985) 123-128, https:// doi.org/10.1080/01430750.1985.9675454.

[19] S. Werner, International review of district heating and cooling, Energy. 137 (2017) 617-631, https://doi.org/10.1016/j.energy.2017.04.045.

[20] Z. Tian, S. Zhang, J. Deng, J. Fan, J. Huang, W. Kong, B. Perers, S. Furbo, Largescale solar district heating plants in Danish smart thermal grid: Developments and recent trends, Energy Convers. Manag. 189 (2019) 67-80, https://doi.org/ 10.1016/j.enconman.2019.03.071.

[21] J. Dannemand Andersen, L. Bødker, M. V. Jensen, Large thermal energy storage at Marstal district heating, in: 18th Int. Conf. Soil Mech. Geotech. Eng. Challenges Innov. Geotech. ICSMGE 2013, 2013: pp. 3351-3354.

[22] T. Schmidt, A. Sørensen, Monitoring Results from Large Scale Heat storages for District Heating in Denmark, in, Int. Conf. Energy Storage (2018) 25-28.

[23] J.E. (PlanEnergi) Nielsen, Solar District Heating: Experiences from Denmark, 2014. http://www.alpconv.org/en/organization/groups/past/WGEnergy/Documents/ WS3/3.Nielsen_PlanEnergi_Solar_District_Heating_in_DK.pdf (accessed 06 July 2021).

[24] D. Bauer, R. Marx, J. Nußbicker-Lux, F. Ochs, W. Heidemann, H. MüllerSteinhagen, German central solar heating plants with seasonal heat storage, Sol Energy. 84 (4) (2010) 612-623, https://doi.org/10.1016/j.solener.2009.05.013.

[25] T. Bruce, L. Lindeberg, S. Roslund, Central Solar Heating Plants With Seasonal Storage, Doc. - Swedish Counc. Build. Res. 76 (1982) 165-174.

[26] T. Schmidt, J. Nußbicker, S. Raab, Monitoring results from German Central Solar Heating Plants with Seasonal Storage, Proc. Sol. World Congr. 2005 Bringing Water to World, Incl. Proc. 34th ASES Annu. Conf. Proc. 30th Natl. Passiv. Sol. Conf. 3 (2005) 1555-1560.

[27] T. Schmidt, D. Mangold, New Steps in Seasonal Thermal Energy Storage in Germany, Ecostock 2006 (2006).

[28] D. Mangold, T. Schmidt, H. Müller-Steinhagen, Seasonal thermal energy storage in Germany, in: Struct. Eng. Int. J. Int. Assoc. Bridg. Struct. Eng., 2004: pp. 230-232. https://doi.org/10.2749/101686604777963739.

[29] F. Ochs, W. Heidemann, H. Müller-Steinhagen, Performance of Large-scale seasonal thermal energy stores, J. Sol. Energy Eng. Trans. ASME. 131 (2009) 0410051-0410057, https://doi.org/10.1115/1.3197842.

[30] T. Schmidt, D. Mangold, Status of Solar Thermal Seasonal Storage in Germany, in: Effstock, Citeseer, 2009.

[31] A. Dénarié, M. Calderoni, M. Muscherà, Technical, financial and Urban potentials for solar district heating in Italy, in: Smart Sustain. Plan. Cities Reg., Springer, 2017: pp. 15-32. https://doi.org/10.1007/978-3-319-44899-2_2.

[32] G. Oliveti, N. Arcuri, Prototype experimental plant for the interseasonal storage of solar energy for the winter heating of buildings: Description of plant and its functions, Sol. Energy. 54 (2) (1995) 85-97, https://doi.org/10.1016/0038-092X (94)00128-Z.

[33] G. Oliveti, N. Arcuri, S. Ruffolo, First experimental results from a prototype plant for the interseasonal storage of solar energy for the winter heating of buildings, Sol. Energy. 62 (4) (1998) 281-290, https://doi.org/10.1016/S0038-092X(98)000115. 
[34] I.N.G.F. Fidanza, The first Italian experience on solar district heating in Varese, in: Proc. Int. SDH Conf. 2015, 2015.

[35] M. Guadalfajara, M.A. Lozano, L.M. Serra, Simple calculation tool for central solar heating plants with seasonal storage, Sol. Energy. 120 (2015) 72-86, https://doi. org/10.1016/j.solener.2015.06.011.

[36] D. Olsthoorn, F. Haghighat, P.A. Mirzaei, Integration of storage and renewable energy into district heating systems: A review of modelling and optimization, Sol. Energy. 136 (2016) 49-64, https://doi.org/10.1016/j.solener.2016.06.054.

[37] S.A. Klein et al, TRNSYS 17: A Transient System Simulation program, Solar Energy Laboratory, University of Wisconsin, Madison, USA, Trnsys. (2010). http://sel.me. wisc.edu/trnsys (accessed 06 July 2021).

[38] V. Panthalookaran, M.F. El-Amin, W. Heidemann, H. Müller-Steinhagen, Calibrated models for simulation of stratified hot water heat stores, Int. J. Energy Res. 32 (7) (2008) 661-676, https://doi.org/10.1002/er.v32:710.1002/er.1423.

[39] C. Chang, Z. Wu, H. Navarro, C. Li, G. Leng, X. Li, M. Yang, Z. Wang, Y. Ding, Comparative study of the transient natural convection in an underground water pit thermal storage, Appl. Energy. 208 (2017) 1162-1173, https://doi.org/10.1016/j. apenergy.2017.09.036.

[40] J. Fan, J. Huang, A. Chatzidiakos, S. Furbo, Experimental and theoretic investigations of thermal behavior of a seasonal water pit heat storage, in: ISES Sol World Congr. 2017 - IEA SHC Int. Conf. Sol. Heat. Cool. Build. Ind. 2017, Proc., 2017: pp. 714-725. https://doi.org/10.18086/swc.2017.13.03.

[41] EDSL, EDSL Tas (2016). https://www.edsl.net/tas-engineering/ (accessed 06 July 2021).

[42] Comsol-Multiphysics, COMSOL Multiphysics ${ }^{\circledR}$ v. 5.2, Stock. Sweden. (2016). www.comsol.com (accessed 06 July 2021).

[43] Google, Sattelite image from Google Maps, (2018) (accessed 06 July 2021).

[44] ASHRAE, International Weather For Energy Calculations, Version 2, (2011).

[45] UNI, UNI/TS 11300 - 1 Part 1: Evaluation of energy need for space heating and cooling, Stand. UNI/TS. (2008) 11300-11301.

[46] E. Fuentes, L. Arce, J. Salom, A review of domestic hot water consumption profiles for application in systems and buildings energy performance analysis, Renew. Sustain. Energy Rev. 81 (2018) 1530-1547, https://doi.org/10.1016/j. rser.2017.05.229.

[47] C\&G ENERGY S.R.L, PANNELLO SKY PRO $10 \mathrm{cpc}$ 58. http://www.solarkeymark. nl/DBF/ (accessed 06 July 2021).

[48] G. Li, Sensible heat thermal storage energy and exergy performance evaluations, Renew. Sustain. Energy Rev. 53 (2016) 897-923, https://doi.org/10.1016/j. rser.2015.09.006.
[49] Amaya V. Novo, Joseba R. Bayon, Daniel Castro-Fresno, Jorge RodriguezHernandez, Review of seasonal heat storage in large basins: Water tanks and gravel-water pits, Appl. Energy. 87 (2) (2010) 390-397, https://doi.org/10.1016/ j.apenergy.2009.06.033.

[50] T. Schmidt, D. Mangold, The multi-functional heat storage in Hamburg-Bramfeld innovative extension of the oldest German solar energy housing estate, Conf. Proc. "5th Int. Renew. Energy Storage Conf. (IRES 2010). (2010) 0-5.

[51] F. Ochs, W. Heidemann, H. Müller-Steinhagen, Effective thermal conductivity of moistened insulation materials as a function of temperature, Int. J. Heat Mass Transf. 51 (3-4) (2008) 539-552, https://doi.org/10.1016/j. ijheatmasstransfer.2007.05.005.

[52] BINE Informationsdienst, Summer sun against the winter cold, (2011) 1-4. https:// idw-online.de/en/news431582 (accessed 06 July 2021).

[53] EW-HT. https://www.melcohit.com/en/products/1660/water-to-water-heatpumps-heating-only-very-high-temperature-water-production (accessed 06 July 2021).

[54] COMSOL Multiphysics, Heat Transfer Module, Manual. (2016) 1-222. https://doc. comsol.com/ (accessed 06 July 2021).

[55] COMSOL, CFD module - User Guide (2016). https://doc.comsol.com/ (accessed 06 July 2021)

[56] M. Staniec, H. Nowak, The application of energy balance at the bare soil surface to predict annual soil temperature distribution, Energy Build. 127 (2016) 56-65, https://doi.org/10.1016/j.enbuild.2016.05.047.

[57] M. Li, Y. Jiang, C.F.M. Coimbra, On the determination of atmospheric longwave irradiance under all-sky conditions, Sol. Energy. 144 (2017) 40-48, https://doi. org/10.1016/j.solener.2017.01.006.

[58] K. Hanses, Basics Concrete Construction, Birkhäuser (2017), https://doi.org/ $10.1515 / 9783035612783$.

[59] Nordtex expanded glass granules. https://www.nordtex.it/wp-content/uploads/ 2017/04/NORDTEX_VITREX_ghiaia_di_vetro_cellulare_scheda_tecnica_2016.pdf (accessed 06 July 2021).

[60] F. Ochs, W. Heidemann, H. Muller-Steinhagen, Effective Thermal Conductivity of the Insulation of High Temperature Underground Thermal Stores During Operation, in, Ecostock (2006, 2006,) 1-7.

[61] M. Jerman, R. Černý, Effect of moisture content on heat and moisture transport and storage properties of thermal insulation materials, Energy Build. 53 (2012) 39-46, https://doi.org/10.1016/j.enbuild.2012.07.002. 